\title{
Genome-wide identification and expression profiling of SET DOMAIN GROUP family in Dendrobium catenatum
}

\author{
Dong-Hong Chen ${ }^{1 *+}$, Han-Lin Qiu ${ }^{1 \dagger}$, Yong Huang ${ }^{2}$, Lei Zhang ${ }^{1}$ and Jin-Ping Si ${ }^{1 *}$
}

\begin{abstract}
Background: Dendrobium catenatum, as a precious Chinese herbal medicine, is an epiphytic orchid plant, which grows on the trunks and cliffs and often faces up to diverse environmental stresses. SET DOMAIN GROUP (SDG) proteins act as histone lysine methyltransferases, which are involved in pleiotropic developmental events and stress responses through modifying chromatin structure and regulating gene transcription, but their roles in $D$. catenatum are unknown.

Results: In this study, we identified 44 SDG proteins from D. catenatum genome. Subsequently, comprehensive analyses related to gene structure, protein domain organization, and phylogenetic relationship were performed to evaluate these D. catenatum SDG (DcSDG) proteins, along with the well-investigated homologs from the model plants Arabidopsis thaliana and Oryza sativa as well as the newly characterized 42 SDG proteins from a closely related orchid plant Phalaenopsis equestris. We showed DcSDG proteins can be grouped into eight distinct classes $($ ( $~ V I I$ and $M)$, mostly consistent with the previous description. Based on the catalytic substrates of the reported SDG members mainly in Arabidopsis, Class I (E(z)-Like) is predicted to account for the deposition of H3K27me2/3, Class II (Ash-like) for H3K36me, Class III (Trx/ATX-like) for H3K4me2/3, Class M (ATXR3/7) for H3K4me, Class IV (Su (var)-like) for H3K27me1, Class V (Suv-like) for H3K9me, as well as class VI (S-ET) and class VII (RBCMT) for methylation of both histone and non-histone proteins. RNA-seq derived expression profiling showed that DCSDG proteins usually displayed wide but distinguished expressions in different tissues and organs. Finally, environmental stresses examination showed the expressions of DCASHR3, DCSUVR3, DCATXR4, DCATXR56, and DCSDG49 are closely associated with drought-recovery treatment, the expression of DCSUVH5a, DCATXR5a and DCSUVR14a are significantly influenced by low temperature, and even 61\% DCSDG genes are in response to heat shock.
\end{abstract}

Conclusions: This study systematically identifies and classifies SDG genes in orchid plant D. catenatum, indicates their functional divergence during the evolution, and discovers their broad roles in the developmental programs and stress responses. These results provide constructive clues for further functional investigation and epigenetic mechanism dissection of SET-containing proteins in orchids.

Keywords: SDG, SET domain, Histone lysine methylation, Expression profiling, Environmental stress

\footnotetext{
*Correspondence: donghong.chen@zafu.edu.cn; Issjp@163.com

${ }^{\dagger}$ Dong-Hong Chen and Han-Lin Qiu contributed equally to this work.

${ }^{1}$ State Key Laboratory of Subtropical Silviculture, SFGA Engineering Research

Center for Dendrobium catenatum (D. officinale), Zhejiang A\&F University,

Lin'an, Hangzhou 311300, Zhejiang, China

Full list of author information is available at the end of the article
}

(c) The Author(s). 2020 Open Access This article is distributed under the terms of the Creative Commons Attribution 4.0 International License (http://creativecommons.org/licenses/by/4.0/), which permits unrestricted use, distribution, and reproduction in any medium, provided you give appropriate credit to the original author(s) and the source, provide a link to the Creative Commons license, and indicate if changes were made. The Creative Commons Public Domain Dedication waiver (http://creativecommons.org/publicdomain/zero/1.0/) applies to the data made available in this article, unless otherwise stated. 


\section{Background}

Spatiotemporal expression patterns of a set of genes associated with developmental and environmental stimuli are largely regulated by epigenetic modifications, which mainly consist of DNA methylation, non-coding RNAs, chromatin remodeling and histone modifications [1]. Histone modifications may occur post-translationally on various residues in histone tails and core regions. These modifications mainly include methylation, acylation, phosphorylation, ubiquitination, citrullination, hydroxylation, O-GlcNAcylation and ADP-ribosylation [2, 3], which constitute different combinations, that is, "histone code", and act in chromatin-templated processes [4, 5]. Among these covalent modifications, histone methylation displays complicated features as it not only occurs on distinct residues (lysine and arginine) and positions, but also involves different numbers (1 3) of methyl groups [6]. Histone lysine modification is catalyzed by histone lysine methyltransferases (HKMTases) / SET DOMAIN GROUP (SDG) proteins which commonly possess an evolutionarily conserved SET domain as catalytic module [7], except for H3K79 methyltransferase DOT1, which lacks a SET domain [8]. SDG-catalyzed histone methylation at specific lysine residues can cause similar or opposite effects on gene expression, such as those of H3K4 and H3K36 associated with gene activation, whereas those of H3К9, Н3К27, H4К20 associated with gene repression [9].

Based on the sequence homology and phylogenetic reconstruction, plant SDG proteins can be categorized into seven distinct classes: class I, E(z) homologs (H3K27me writer); class II, ASH1 homologs (H3K36me writer); class III, Trx homologs and related proteins (H3K4me writer); class IV, proteins with a SET domain and a PHD domain; class $\mathrm{V}, \mathrm{Su}$ (var) homologs and relatives (H3K9me writer); class VI, proteins with an interrupted SET domain (S-ET); class VII, Ribulose-1,5-bisphosphate carboxylase/oxygenase (Rubisco) methyltransferase (RBCMT) and other SET related proteins for targeting non-histone proteins $[10,11]$. SDG genes have been discovered in bacteria, viruses, and eukaryotes [12, 13]. The presence of SDG genes in bacteria was initially considered a consequence of horizontal gene transfer from eukaryotic hosts $[14,15]$. However, investigation on more released genomes of prokaryotic organisms including not only pathogens and symbionts, but also freeliving bacteria and archaea suggests that SDG genes have undergone independent evolution in prokaryotes, and this event is unrelated to the evolution of eukaryotic SDGs, on the other hand, an ancient horizontal gene transfer occurred between bacteria and archaea $[13,16]$.

SDG family has currently been systematically identified and classified in the genomes of Arabidopsis (49 members) [10, 17], Brassica rapa (49) [11], Vitis vinifera (33)
[18], Populus trichocarpa (59) [19], Zea mays (43) [20], Oryza sativa (43) [21], Solanum lycopersicum (52) [22], Citrus sinensis (47) [23], Gossypium raimondii (52) [24], C4 panicoid model Setaria italica (53) [25], and Litchi chinensis (48) [26]. However, the SDG family in orchid species, which constitute an extremely evolutionary branch, remains elusive.

SDG proteins and related histone methylation marks are widely involved in diverse growth and developmental processes, such as seed dormancy, repression of vegetative-to-embryonic reversion, shoot branching, root system architecture, chloroplast development, flowering time, vernalization, floral organ development, ovule and anther development, embryo and endosperm development, plant senescence, carotenoid biosynthesis, and thigmomorphogenesis [27-32]. They are also implicated in the response to biotic and abiotic stresses. SDG8 is required for plant defense against necrotrophic fungal pathogens by regulating a subset of genes within jasmonic acid (JA) and/or ethylene signaling pathway [27] and for basal and $\mathrm{R}$ protein-mediated resistance to bacterial pathogens in Arabidopsis [33]. Loss-of-function mutant $s d g 8$ results in enhanced susceptibility to the fungal and bacterial pathogens. ARABIDOPSIS TRITHORAX-LIKE PROTEIN1 (ATX1) as H3K4me3 writer orchestrates expression of defense response genes in antagonistic salicylic acid (SA)/JA signaling pathways by directly activating the expression of the SA/JA signaling mediator WRKY70 gene through establishing H3K4me3 marks on its nucleosomes [34]. In addition, ATX1 is involved in drought stress response, and its disruption results in decreased tolerance to dehydration stress in atx1 plants [35]. ATX1 modulates dehydration stress signaling in both abscisic acid (ABA)-dependent and -independent pathways. During ABA-dependent pathway, dehydration stress induces ATX1 binding to NCED3 locus, which encodes the rate-limiting enzyme in ABA biosynthesis. Subsequently the deposition of H3K4me3 mark and recruitment of RNA polymerase II are increased, leading to enhanced NCED3 expression and ABA production [36]. Dehydration stress causes dynamic and specific changes in global histone H3K4me1/2/3 patterns in Arabidopsis, especially H3K4me3 marks with broad distribution profiles on the nucleosomes of stress-induced genes [37]. Similarly, drought stress triggers massive changes in $\mathrm{H} 3 \mathrm{~K} 4 \mathrm{me} 3$ enrichments on numerous loci (respectively including $3927 / 910$ genes with increased/decreased depositions) in rice seedlings, showing positive correlation with their transcript changes in response to drought stress [38]. However, when Arabidopsis exposed to cold temperatures, H3K27me3 deposition gradually decreases in the chromatins of two cold-responsive genes, COR15A and ATGOLS3 [39]. 
Dendrobium catenatum (also known as Dendrobium officinale) belongs to the Orchidaceae family, is a rare and precious Chinese medicinal herb. The stem of $D$. catenatum is the major medicinal part used for relieving upset stomach, promoting body fluid production, and nourishing Yin and antipyresis in traditional remedy and health care [40]. Furthermore, the plant stem contains bioactive extracts with anticancer, hepatoprotective, hypolipidemic, antifatigue, antioxidant, anticonstipation, hypoglycemic, gastric ulcer-protective, and antihypertensive effects, and immunoenhancement, as confirmed by modern pharmacology [41]. However, given its longtime extensive demand and over-exploitation, $D$. catenatum suffers from near extinction, and was once defined as an endangered medicinal plant in China [42]. In the past 20 years, $D$. catenatum has been successfully cultivated and became an important economic crop for health care. Unfortunately, environmental stresses, such as drought, cold, and high temperature, extremely restrict its growth, resulting in heavy yield loss [43]. Hence, it is necessary to screen and identify the candidate genes conferring resistance to differential environmental stresses in D. catenatum molecular breeding.

To obtain a detailed understanding on the SDG family in medicinal orchid plants, we identified SDG members throughout the genome of $D$. catenatum, and subsequently performed comprehensive assessments on the phylogenetic relationship, gene structure, domain organization, gene expression profiling, and response to environmental stresses. Our results provide insights into the evolution and function of SDG genes in medicinal orchid plants.

\section{Results}

\section{Identification of SDG proteins in the $D$. catenatum genome}

To obtain all the members of SDG proteins in D. catenatum, we performed BLASTP search using known Arabidopsis and rice SDG proteins as queries against the $D$. catenatum genome (INSDC: JSDN00000000.2). First, we checked the SDG genes of Arabidopsis and rice in the Superfamily 1.75 database (http://supfam.org/SUPER FAMILY/). We discovered 49 genes in Arabidopsis thaliana, corresponding to those reported in literature (Additional file 1) [10, 17]. On the other hand, 46 genes were identified in Oryza sativa (Additional file 1), three (Os01g65730/OsSET44, Os01g74500/OsSET45, Os06g03676/OsSET46) more than the 43 reported genes [21]. Reciprocal BLAST was carried out to confirm that the hits from $D$. catenatum and its close relative Phalaenopsis equestris belong to the SDG family. Finally, we obtained 44. SDG genes in D. catenatum (Table 1 and Fig. 1) and 42 in P. equestris (Additional file 2), and they were named after their Arabidopsis homologs.
To characterize and classify the SDG family in $D$. catenatum, we used SDG proteins in the dicot model plant A. thaliana, the monocot model plant $O$. sativa, and its close relative $P$. equestris as references for phylogenetic analysis. The results showed that the 181 SDG proteins from the above four species could be clustered into eight classes (I VII and M), mostly corresponding to the classification criteria in Arabidopsis [10]. By contrast, ARABIDOPSIS TRITHORAX RELATED 3 (ATXR3) branch was previously classified into Class III [10], but it was separated from the other branches and near ATXR7-like proteins in Class IV in this study (Fig. 1). Considering their similar substrate specificities, we combined ATXR3 branch and the neighboring ATXR7-like proteins and categorized them under class $M$, as supported by the further phylogenetic analysis among Classes III, IV, and M (Fig. 4). Given the high limited reports on Class VI and VII, which feature potential functions for nonhistone and histone methylation, we mainly focused on the roles of Classes $\mathrm{I} \sim \mathrm{V}$ and $\mathrm{M}$ with well-investigated histone methylation specificity in this study.

\section{Class I: E(z)-like (H3K27me2/3)}

Class I contains two $\mathrm{E}(\mathrm{z})$ homologs in each of monocot plants $D$. catenatum, $P$. equestris and rice, and three wellcharacterized homologs, namely, CURLY LEAF (CLF), SWINGER (SWN), and MEAEA (MEA), that represent three distinct clades in the dicot plant Arabidopsis (Fig. 2). The genes in this class contain 15 16 introns, which are extremely longer in the two orchid species compared with those of Arabidopsis and rice. This result suggests that overall intron length positively correlated with the corresponding genome size. A similar phenomenon related to intron/exon proportion was also observed in the members of the other classes as will be mentioned later. The three Arabidopsis $\mathrm{E}(\mathrm{z})$ proteins act as the catalytic subunits of the evolutionarily conserved Polycomb Repressive Complex 2 (PRC2), which is involved in the deposition of H3K27me3 repressive mark on the target gene locus [44]. CLF (dominant H3K27me3 writer) and SWN act redundantly in vegetative and reproductive development, whereas MEA functions exclusively in suppression of central cell proliferation and endosperm development [45-47]. Rice E(z) homologs SDG711 and SDG718 participate in mediating accurate photoperiod control of flowering time [48]. Clades I-1 (CLF-like) and I-2 (SWN-like) each contain one ortholog in the examined species, but Clade I-3 (MEA-like) is confined to Arabidopsis. Plant E(z)-like proteins generally harbor highly conserved domain organization at the $\mathrm{C}$-terminal region, which includes a SANT domain, the cysteine rich CXC domain, and the signature SET domain, except for DcCLF and PeSWN, which lack the SANT domain, and DcSWN, which possesses an additional SANT domain at the $\mathrm{N}$-terminus. 
Table 1 Classification of SDG genes in D. catenatum

\begin{tabular}{|c|c|c|c|c|c|c|}
\hline No. & Name & Gene ID & Clade & exon number & Protein (aa) & Isoform \\
\hline 1 & DCCLF & LOC110113338 & I & 16 & 918 & 2 \\
\hline 2 & DcSWN & LOC110098601 & । & 17 & 895 & 0 \\
\hline 3 & DCASHH1 & LOC110107485 & $\|$ & 10 & 498 & 0 \\
\hline 4 & DCASHH2 & LOC110097541 & $\|$ & 18 & 1992 & 0 \\
\hline 5 & DcASHH3a & LOC110095009 & $\|$ & 9 & 377 & 0 \\
\hline 6 & DcASHH3b & LOC110105604 & $\|$ & 9 & 235 & 0 \\
\hline 7 & DCASHR3 & LOC110103080 & $\|$ & 11 & 487 & 1 \\
\hline 8 & DcATX1 & LOC110096723 & III & 25 & 1081 & 0 \\
\hline 9 & DcATX3a & LOC110094707 & III & 22 & 980 & 0 \\
\hline 10 & DcATX3b & LOC110093543 & III & 24 & 1060 & 0 \\
\hline 11 & DCATX3C & LOC110116505 & III & 26 & 942 & 4 \\
\hline 12 & DCATX3d & LOC110100284 & III & 19 & 2038 & 0 \\
\hline 13 & DCATXR3 & LOC110093028 & M & 21 & 2360 & 0 \\
\hline 14 & DCATXR7 & LOC110110427 & M & 24 & 1304 & 6 \\
\hline 15 & DcATXR5a & LOC110100023 & IV & 7 & 413 & 3 \\
\hline 16 & DcATXR5b & LOC110102586 & IV & 8 & 373 & 3 \\
\hline 17 & DcATXR6 & LOC110107042 & IV & 4 & 268 & 0 \\
\hline 18 & DcSUVH1a & LOC110091884 & V & 3 & 682 & 0 \\
\hline 19 & DcSUVH1b & LOC110100064 & V & 3 & 680 & 1 \\
\hline 20 & DcSUVH2a & LOC110104355 & V & 3 & 664 & 1 \\
\hline 21 & DcSUVH2b & LOC110111597 & V & 2 & 640 & 0 \\
\hline 22 & DcSUVH4 & LOC110103468 & V & 20 & 752 & 4 \\
\hline 23 & DcSUVH45 & LOC110096224 & V & 2 & 765 & 1 \\
\hline 24 & DcSUVH5a & LOC110109813 & V & 2 & 1048 & 1 \\
\hline 25 & DcSUVH5b & LOC110101480 & V & 2 & 1099 & 0 \\
\hline 26 & DcSUVR14a & LOC110104063 & V & 13 & 783 & 8 \\
\hline 27 & DcSUVR14b & LOC110097487 & V & 9 & 668 & 0 \\
\hline 28 & DCSUVR14C & LOC110097357 & V & 8 & 785 & 0 \\
\hline 29 & DCSUVR3 & LOC110096832 & V & 2 & 337 & 0 \\
\hline 30 & DCSUVR4 & LOC110109382 & V & 13 & 723 & 8 \\
\hline 31 & DcSUVR5 & LOC110092659 & V & 14 & 1658 & 2 \\
\hline 32 & DCASHR1 & LOC110098638 & $\mathrm{VI}$ & 14 & 496 & 0 \\
\hline 33 & DCASHR2 & LOC110112079 & $\mathrm{VI}$ & 3 & 385 & 2 \\
\hline 34 & DcATXR1 & LOC110097453 & $\mathrm{VI}$ & 1 & 521 & 0 \\
\hline 35 & DCATXR2 & LOC110107001 & $\mathrm{VI}$ & 15 & 494 & 0 \\
\hline 36 & DcATXR4 & LOC110103199 & $\mathrm{Vl}$ & 8 & 339 & 0 \\
\hline 37 & DcSDG42 & LOC110104315 & $\mathrm{Vl}$ & 14 & 765 & 4 \\
\hline 38 & DcSDG45 & LOC110107875 & VII & 6 & 490 & 0 \\
\hline 39 & DcSDG46 & LOC110111739 & VII & 6 & 494 & 1 \\
\hline 40 & DcSDG47 & LOC110091896 & VII & 11 & 556 & 2 \\
\hline 41 & DcSDG48 & LOC110099042 & VII & 12 & 499 & 0 \\
\hline 42 & DcSDG49 & LOC110092290 & VII & 16 & 476 & 5 \\
\hline 43 & DcSDG50 & LOC110113229 & VII & 8 & 482 & 2 \\
\hline 44 & DcSDG51 & LOC110094849 & VII & 13 & 503 & 0 \\
\hline
\end{tabular}




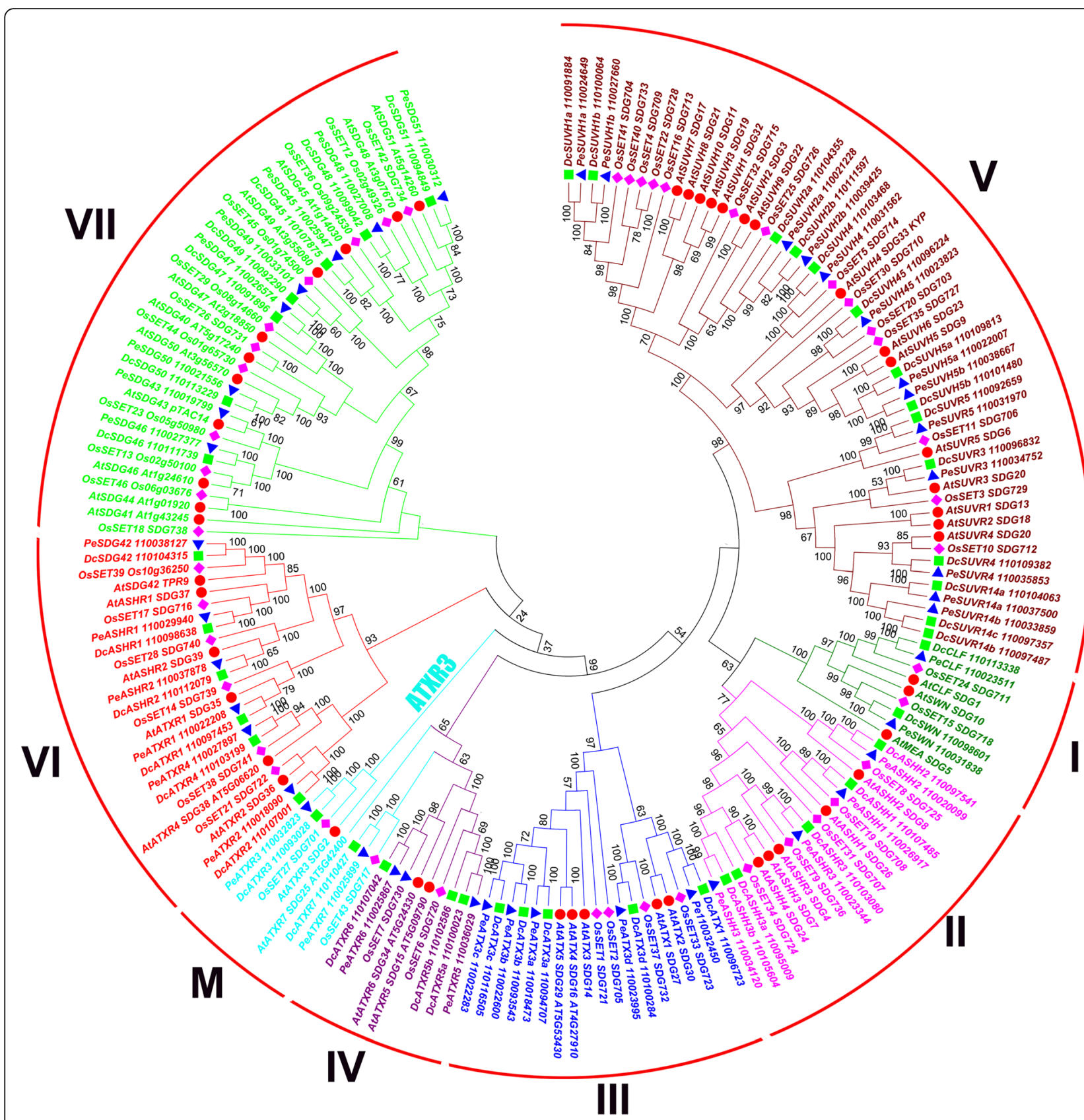

Fig. 1 Phylogenetic analysis of SDGs in D. catenatum, P. equestris, Arabidopsis and rice. This tree includes 44 SET domain-containing proteins from D. catenatum, 42 from $P$. equestris, 49 from $A$. thaliana and 46 from $O$. sativa. The 181 SET domain-containing proteins were divided into eight classes combined with the further phylogenetic analysis in Fig. 4. SDGs amino acid sequences were aligned using Clustalx, and the phylogenetic tree was constructed using MEGA7 with the following settings: Tree Inference as Neighbor-Joining (NJ); Include Sites as Pairwise deletion option for total sequence analyses; Substitution Model: p-distance; and Bootstrap test of 1000 replicates for internal branch reliability. Bootstrap values > $50 \%$ are shown. Dc, D. catenatum; Pe, P. equestris; At, A. thaliana; Os, O. sativa

\section{Class II: ash-like (H3K36me)}

Class II can be further divided into five clades, each of which consists of a single member per plant species, except for two members of Clade II-1 in Arabidopsis and D. catenatum (Fig. 3). Clades II-1 to II-4 exist in all the examined species, but Clade II- 5 is only found in rice and contains a single member, SDG707, with unknown function. Class II proteins generally share three conserved domains: an Associated with SET (AWS), SET, and PostSET domains $[10,49]$.

Clade II-1 (ASHH3-like) members are relatively shorter than their homologs in the four other clades. Arabidopsis ASHH3/SDG7 is required for proper timing in response to vernalization [50]. SDG7 lacks detectable HKMTase 


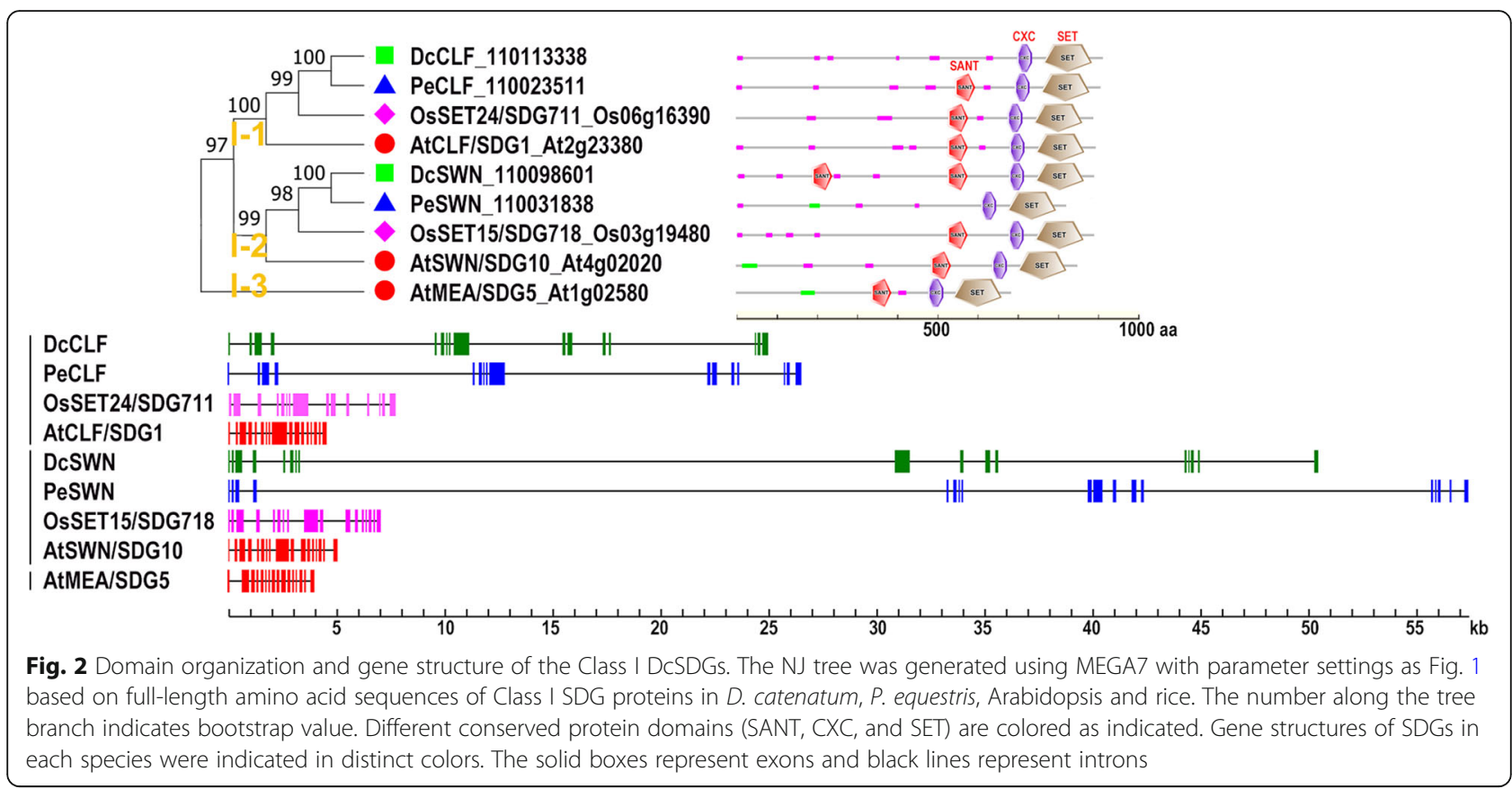

activity [51], but rice ortholog SDG724/LVP possesses H3K36 methylation activity. The loss of SDG724 leads to late flowering [52]. Notably, DcASHH3a/3b in D. catenatum lack AWS domain, different from PeASHH3 from its close relative P. equestris and ASHH3 orthologs in Arabidopsis and rice, and their functional divergence during speciation is interesting to investigate.

Clade II-2 (ASHR3-like) members are characterized by an additional PHD domain near the N-terminus, except for rice SDG736. ASHR3/SDG4 participates in regulating pollen tube growth and stamen development, and its overexpression leads to growth arrest and male sterility [53, 54]. ASHR3 harbors catalytic activities on H3K36me1 and possible H3K36me2, which is involved in regulating cell division competence in the root meristem [55].

Clade II-3 (ASHH1-like) members display uniform protein length and highly conserved AWS-SET-PostSET domain combination at the $\mathrm{N}$-terminus. Arabidopsis ASHH1/SDG26 knockout leads to a late-flowering phenotype through decreasing H3K4me3 and H3K36me3 level at the SOC1 locus [56, 57]. Similarly, the knockdown of rice ortholog $S D G 708$ causes a late-flowering phenotype and a genome-wide decrease in $\mathrm{H} 3 \mathrm{~K} 36 \mathrm{me} 1 / 2 / 3$ levels during early growth stages [58]. Predictably, D. catenatum DcASHH1 harbors a similar function.

Clade II-4 (ASHH2-like) proteins are considerably longer than the others, and characterized by an additional $\mathrm{CW}$ domain near to the $\mathrm{N}$-terminal triple domain combination. Arabidopsis ASHH2/SDG8 acts as the major H3K36me2/3 writer [57, 59], and its knockout leads to pleiotropic phenotypes in vegetative and reproductive stage [60]. Consistently, the knockdown of rice ortholog
SDG725 causes wide-ranging defects, including dwarfism, erect leaves and small seeds [32]. In the aspect of protein architecture, ASHH2 ortholog in D. catenatum or $P$. equestris is more like Arabidopsis SDG8 than rice SDG725.

\section{Class III: Trx/ATX-like (H3K4me2/3)}

Class III consists of five members, which can be further divided into three clades in each examined plant species (Fig. 4). Class III proteins are characterized by tandem PHD domains in the middle region and SET-PostSET domain combination at the $\mathrm{N}$-terminus. Moreover, several clades contain additional distinct domains, such as PWWP domain specific to Clade III-1/2, and FYRNFYRC domain combination specific to Clade III-1.

Clade III-1 (ATX1-like) contains two members in Arabidopsis, and one in each of the three other species. In Arabidopsis, ATX1 and ATX2 paralogs exhibit similar domain architectures [61], but have distinct expression patterns in most cases and influence the expressions of largely nonoverlapping gene sets [62]. For the shared targets, ATX1 and ATX2 account for the deposition of H3K4me3 and H3K4me2 marks, respectively [62]. Different from Arabidopsis atx1 with early-flowering phenotype [62], rice ortholog mutant ostrx1/sdg723 exhibits late-flowering through decreased H3K4me3 levels at the central flowering time integrator Ehd1. OsTRX1 can rescue Arabidopsis atx1 phenotype [63-65], suggesting that ATX1-like proteins demonstrate conserved biochemical and molecular functions during evolution. However, ATX1-like proteins produce specific phenotypes in distinct species due to the differences in developmental 


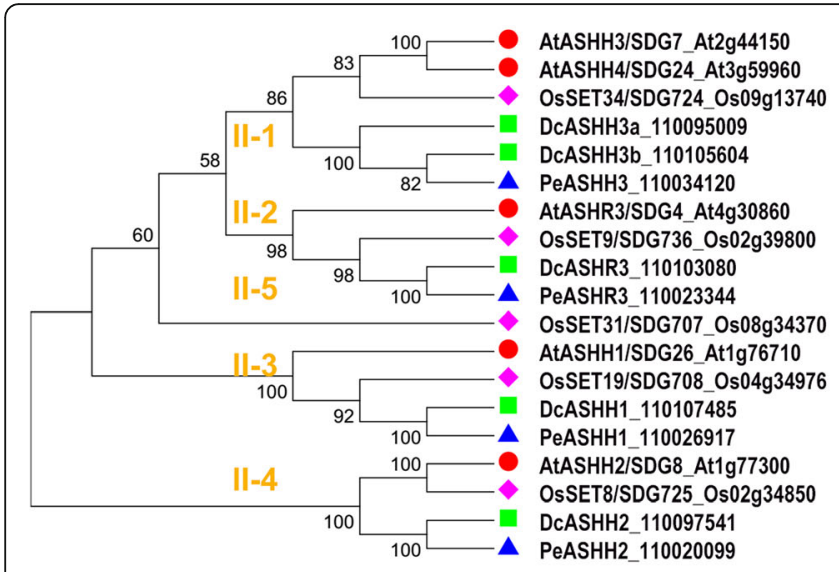

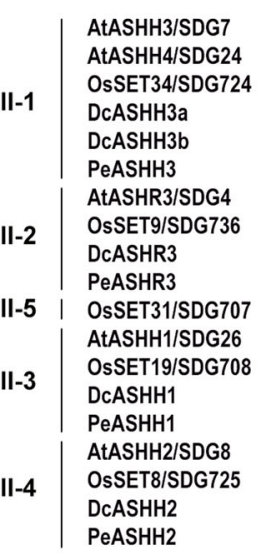

\section{HWIIfI}

패네
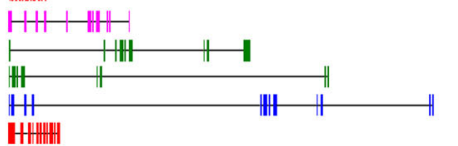

$H+11$
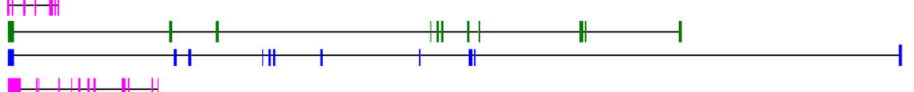

$\|+\mathrm{H}-\mathrm{H}-\mathrm{H}$

HWHIII

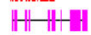

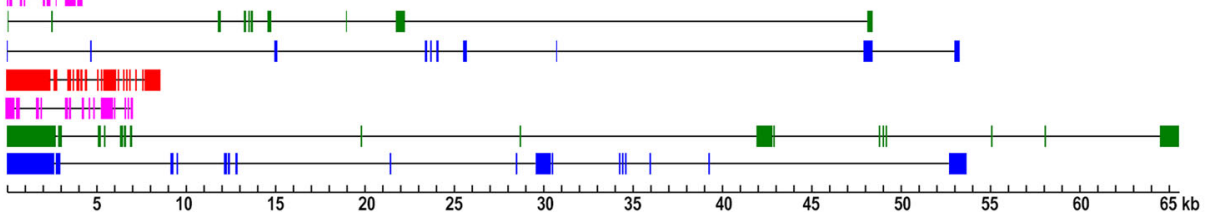

Fig. 3 Domain organization and gene structure of the Class II SDGs. The NJ tree was generated using MEGA7 with parameter settings as Fig. 1 based on full-length amino acid sequences of Class II SDG proteins in D. catenatum, P. equestris, Arabidopsis and rice. The number along the tree branch indicates bootstrap value. Different conserved protein domains (AWS, PHD, zf-CW, SET and PostSET) are colored as indicated. Gene structures of SDGs in each species were indicated in distinct colors. The solid boxes represent exons and black lines represent introns

context. Thus, DcATX1 and PeATX1 in orchid may play important roles in flowering time control.

Clade III-2 (ATX3-like) includes three members in each tested species. Arabidopsis ATX3/4/5 are clustered together and separated from the monocot orthologs. The orthologs from $D$. catenatum, and $P$. equestris are consistently clustered together, concordant with their close relationship. In Arabidopsis, ATX3/4/5 exhibit a common evolutionary origin, and function redundantly in genome-wide H3K4me2/3 profiles. Furthermore, at 3 atx4 at $x 5$ triple mutant displays dwarfism and reduced fertility [66]. In rice, ATX3-like proteins SDG721 and SDG705 function redundantly in modulating H3K4 methylation levels. The loss of both genes results in semi-dwarfism [67]. Considering the dwarf phenotype of ATX3-like mutants in Arabidopsis and rice, the homologs in $D$. catenatum and $P$. equestris might be involved in regulating plant architecture.

Clade III-3 shows specificity toward the examined monocots and contains one copy per species. D. catenatum DcATX3d and $P$. equestris PeATX3d are characterized by an additional Jas domain at the Cterminus, in contrast with the rice ortholog OsSET37/ SDG732. Further survey of this clade will provide insights into the evolution of SDG family in monocots.

\section{Class M: ATXR3/7 (H3K4me)}

Class $M$ comprises of two clades, namely, Clade $M-1$ (ATXR7-like) and M-2 (ATXR3-like). Each clade contains one copy per plant species (Fig. 4). ATXR7-like proteins usually lack extra domains, except for PeATXR7 with a Cterminal GYF domain. Arabidopsis ATXR7/SDG25 acts as the writer of H3K4 monomethylation (H3K4me1), and its knockout results in early flowering $[59,68]$. ATXR3like proteins also contain only one copy in each species, are characterized by the presence of DUF4339 domain in the middle region, except for OsSET27/SDG701. Arabidopsis ATXR3/SDG2 is the major H3K4me3 writer, whose depletion leads to pleiotropic development defects $[28,69,70]$. D. catenatum DcATXR3 and P. equestris PeATXR3 feature a more similar protein architecture to Arabidopsis ATXR3/SDG2 than rice SDG701. This 


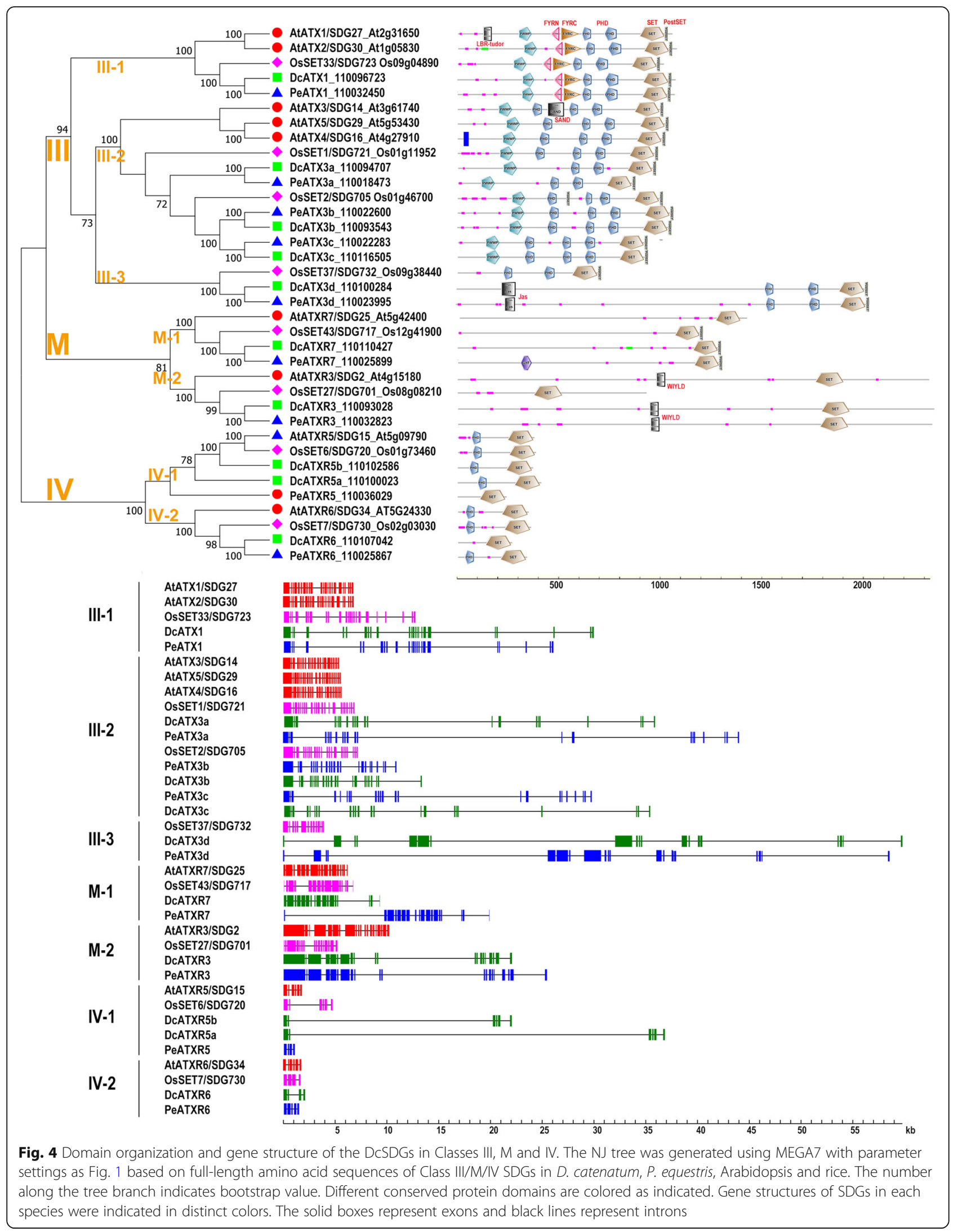


finding suggests that ATXR3-like proteins in orchid may retain their ancestral role, whereas rice ortholog may functionally diverge, as attributed to the loss of specific domain and partial sequence.

\section{Class IV: Su (var)-like (H3K27me1)}

Class IV can be divided into two clades, Clade IV-I (ATXR5-like) and IV-II (ATXR6-like), which are characteristic of an N-terminal PHD domain in addition to the defined SET domain, except for PeATXR5 (Fig. 4). In Arabidopsis, ATXR5 and ATXR6 show largely overlapping functions, and the depletion of both results in global H3K27me1 reduction and heterochromatin decondensation $[71,72]$. ATXR5/6 are involved in maintaining DNA replication [73] and repressing the expression of transposable element [74]. The overexpression of either ATXR5 or ATXR6 causes male sterility [75]. ATXR5 and ATXR6 probably perform separate roles because of ATXR5 with a dual localization in plastids and nucleus but ATXR6 solely in nucleus [75].

\section{Class V: Suv-like (H3K9me)}

Class V contains 15 members in Arabidopsis, 14 in rice and D. catenatum, and 13 in $P$. equestris; These members can be further divided into two subclasses, SUVH and SUVR, which include Clades V-1 to V-3 and V-4 to V-6, respectively (Fig. 5). Class V proteins are usually characterized by PreSET-SET-PostSET or PreSETSET domain combinations. SUVH proteins often contain another symbolic SET- and RING-ASSOCIATED (SRA) domain, whereas SUVR proteins in Clades V-4 and V-5 often include another WIYLD domain and tandem $\mathrm{ZnF}$ $\mathrm{C} 2 \mathrm{H} 2$ domains, respectively. SUVH genes usually lack introns, except for the members of SUVH4 branch and two members (PeSUVH45 and SDG727) of SUVH5 branch, whereas SUVR genes contain variable number of introns. In general, Class $\mathrm{V}$ members are responsible for methylation of histone $\mathrm{H} 3$ lysine 9 (H3K9me), in which H3K9 dimethylation (H3K9me2) is the critical mark for gene silencing and DNA methylation, and are involved in heterochromatin formation and reprogramming of gene expression [76].

\section{SUVH subclass}

In Clade V-1, the five members SUVH1/3/7/8/10 in Arabidopsis cluster together and show distinction from the five homologs in rice and each of the two homologs in $D$. catenatum or $P$. equestris. This result indicates that

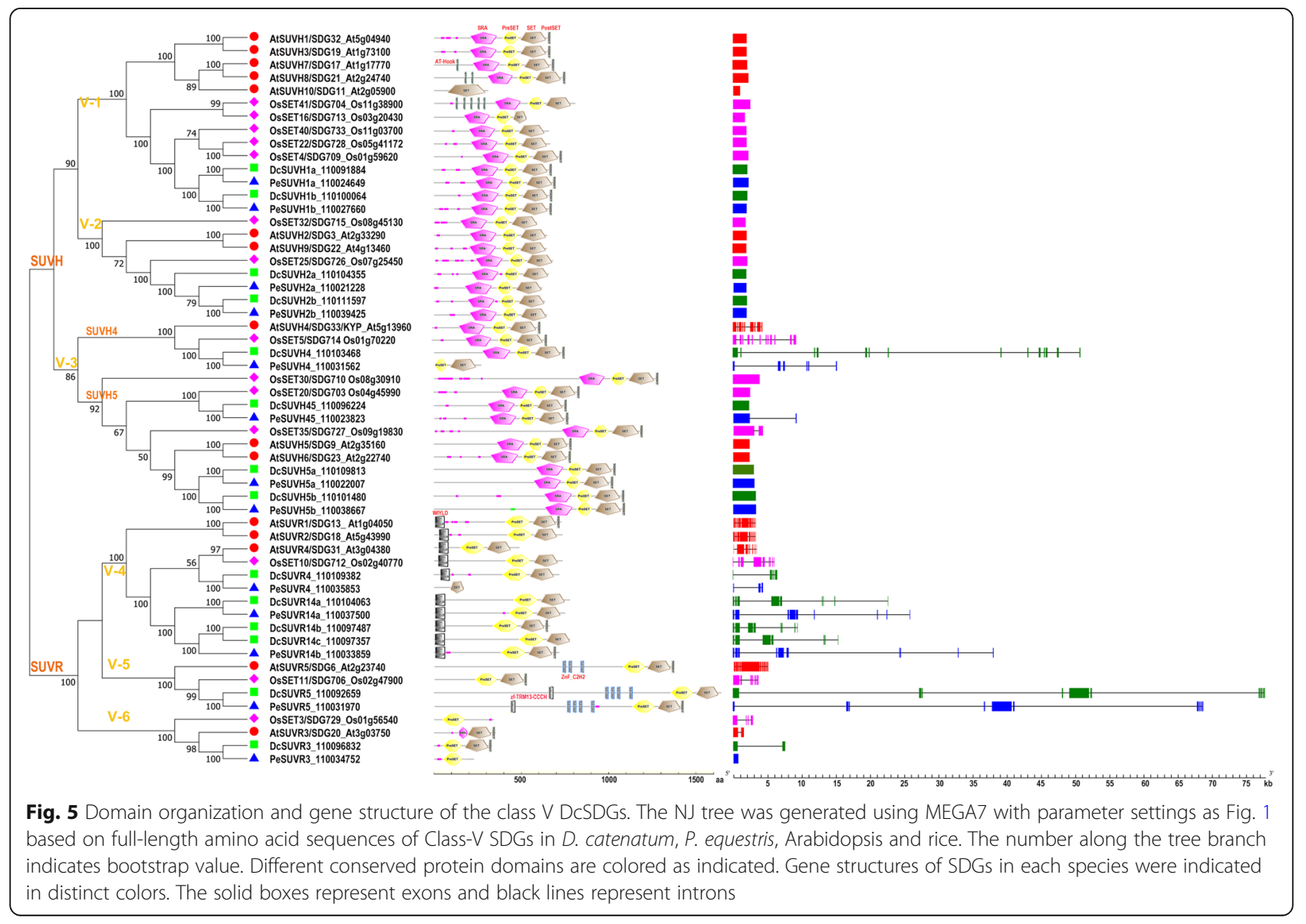


duplication of these clade members occurred after divergence between dicots and monocots. However, the two orthologs in either D. catenatum or P. equestris respectively pair together, indicating that their gene duplication occurred before the split of Dendrobium and Phalaenopsis. Arabidopsis SUVH1/SDG32 performs a distinct antisilencing function to promote the expression of DNA methylation-targeted genes. SUVH1 knockout causes no effect on H3K9me2 levels but reduces H3K4me3 levels [77]. Furthermore, SUVH1 binds to highly methylated genomic loci targeted by RNA-directed DNA methylation (RdDM). However, rice SUVH1-like protein SDG728 retains its classical function to mediate H3K9 methylation and participates in retrotransposon repression [78]. D. catenatum and $P$. equestris include two SUVH1-like proteins, far less than the five members in Arabidopsis and rice. Thus, the function of SUVH1 homologs and the evolutionary mechanisms in orchids require further investigation.

Clade V-2 comprises two members for each examined species, and these members lack PostSET domains, in contrast with those in clade V-1. In Arabidopsis, SUVH2 and SUVH9 as sister paralogs show overlapping functions in $\mathrm{RdDM}$ and heterochromatic gene silencing $[79,80]$. SUVH2 overexpression leads to ectopic heterochromatization accompanied with significant developmental defects, such as extreme dwarfism [79, 81]. SUVH2 and SUVH9 may feature inactive histone methyltransferase activity $[82,83]$. However, the simultaneous absences of SUVH2 and SUVH9 lead to a marked decrease in H3K9me2 levels in the RdDM loci [80, 84]. SUVH2 and SUVH9 can bind to methylated DNA and facilitate the recruitment of Pol V to RdDM loci [82, 84]. Considering the highly similar domain organization among SUVH2-like proteins in these examined species, their function should be evolutionarily conserved.

Clade V-3 proteins could be further divided into two branches (SUVH4 and SUVH5). SUVH4 branch possesses one member in each species, whereas SUVH5 branch contains two members in Arabidopsis and rice, and three members in $D$. catenatum or $P$. equestris. In Arabidopsis, SUVH4/KRYPTONITE (KYP), SUVH5, and SUVH6 as H3K9 methyltransferases, are required to maintain DNA methylation [85-90]. SUVH4 as the predominant H3K9me1/2 writer [76]. SUVH5 and SUVH6 as sister paralogs in SUVH5 branch exhibit HKMTase activities with locus-specific features $[76,86,87]$. In rice, SUVH4-like protein SDG714 mediates H3K9 methylation, participating in DNA methylation, transposition of transposable elements, and genome stability [91]. Notably, PeSUVH4 protein in $P$. equestris is evidently short and lack SRA and PostSET domains, compared with SUVH4-like proteins in the three other species. The divergence of SUVH4 between orchid genus Dendrobium and phalaenopsis is worthy of investigation.

\section{SUVR subclass}

In Clade V-4, there are 3 members in Arabidopsis and $P$. equestris, 1 in rice, and 4 in $D$. catenatum, respectively. In Arabidopsis, SUVR2 mediates transcriptional silencing in both RdDM-dependent and -independent manners [92]. SUVR4 participates in the epigenetic defense mechanism by introducing $\mathrm{H} 3 \mathrm{~K} 9 \mathrm{me} 3$ marks to repress potentially harmful transposon activity [93]. SUVR4 specifically converts $\mathrm{H} 3 \mathrm{~K} 9 \mathrm{me} 1$ into $\mathrm{H} 3 \mathrm{~K} 9 \mathrm{me} 3$ at transposons and pseudogenes within the euchromatin [93, 94], but SUVR1 and SUVR2 show no detected histone methyltransferase activity in vitro $[92,95]$. In this study, $D$. catenatum DcSUVR4, P. equestris PeSUVR4, and rice SDG712 were grouped together with Arabidopsis SUVR4 but not with SUVR1/2, implying that they possess ubiquitin-binding and HKMTase activities, except for PeSUVR4, which includes an obviously short sequence and lacks WIYLD and PreSET domains.

Clade V-5 contains one member in each tested species, and characterized by an additional tandem $\mathrm{ZnF} \_\mathrm{C} 2 \mathrm{H} 2$ domain, except for SDG706. In Arabidopsis, SUVR5 lacks the SRA domain but recognizes specific DNA sequences through its zinc finger motifs and establishes the heterochromatic state through H3K9me2 deposition in a DNA methylation-independent manner [96]. The knockout of SUVR5 leads to delayed flowering, and no further enhanced phenotype occurs in the quintuple suvr1 suvr2 suvr3 suvr4 suvr5 mutants [96, 97]. This finding suggests that SUVR5 is a dominant developmental regulator in SUVR subclass.

Clade V-6 members exist in one copy in each species, and their encoding proteins are notably shorter than those of the other clades in this class. Arabidopsis SUVR3 contains an additional AWS domain close to the SET-PostSET domain combination, and DcSUVR3 contains an intact PreSET-SET-PostSET domain combination. However, SUVR3 orthologs in rice and $P$. equestris only contain a PreSET domain, suggesting that the genes in Clade V-6 may undergo less selective pressures and become increasingly divergent during evolution. The functions of the genes in this clade remain uncharacterized thus far.

\section{Tissue and organ expression profiles of DCSDG genes}

To investigate the potential roles of DcSDGs during growth and development in $D$. catenatum, we detected the expression profiles of DcSDGs by reanalyzing the RNA-seq data from different plant tissues and organs, including leaf, root, green root tip, white part of root, stem, flower bud, sepal, labellum (lip), pollinia, and gynostemium (column) [98].

Based on hierarchical clustering (Fig. 6 and Additional file 3), the expression patterns of DcSDGs could be divided into two groups, G1 and G2. G1 genes usually feature 


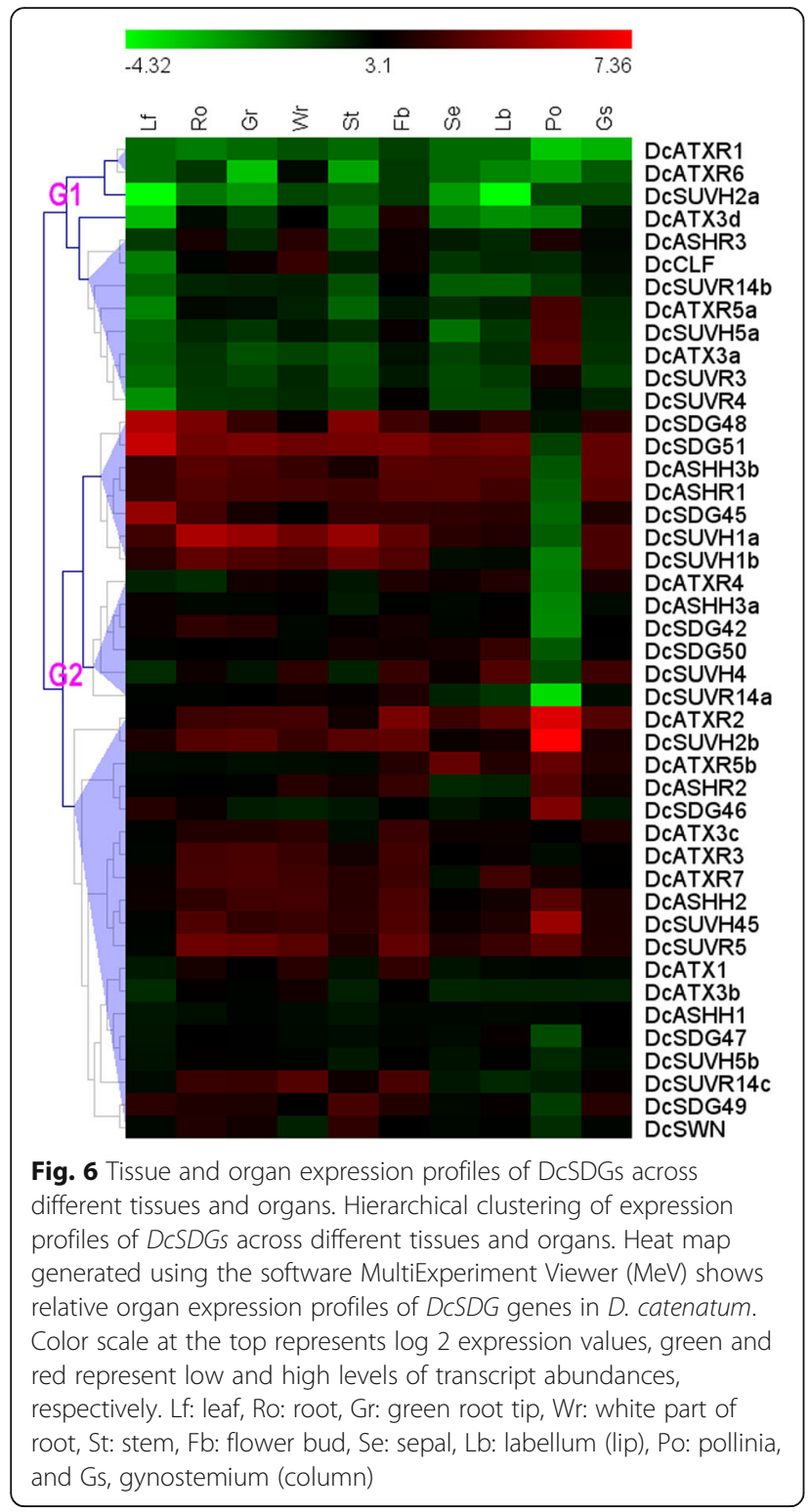

low expressions in most tissues and organs. However, several genes are highly expressed in specific tissues and organs, such as DcATX3d in flower bud, DcASHR3 in root and flower bud, and DcATXR5a,DcSUVH5a, and $D c A T X 3 a$ in pollinia. G2 genes display diverse expression profiles in different tissues and organs. The majority of G2 group genes are highly expressed in most of the detected tissues and organs, whereas several show intermediate expressions in most tissues and organs, such as DcASHH3a, DcASHH1, DcSUVH5b, and DcSDG47. Furthermore, $\sim 86 \%$ of genes $(38 / 44)$ present intermediate and high expressions in flower buds, compared with $\sim 77 \%$ (34) in root and gynostemium, $\sim 57 \%$ (25) in leaf, $\sim 45 \%$ (20) in stem, $\sim 43 \%$ (19) in pollinia, 55\% (24) in sepal, and 64\% (28) in labellum. These findings suggest that DcSDG family plays essential roles in flower bud formation. Notably, DcSDG51 in leaf, DcSUVH $2 b$ in pollinia, and DcSUVH1a in root and stem display the most distinguished expressions, indicating their prominent functions in specific tissues.

The expression profiles of six duplicated DcSDG gene pairs were further compared (Additional file 4). In general, one copy showed higher expression levels than the others in all tissues, except for $D c S U V H 5 a / 5 b$ pairs, suggesting that one paralog might performed a dominant function during plant growth and development. DcASHH3a/3b, $D c A T X 3 b / 3 c, D c A T X R 5 a / 5 b$ and DcSUVR14b/14c exhibited similar expression patterns, whereas DcSUVH5a/5b pairs displayed differential expression profiles in the detected tissues and organs. These results indicate that distinct duplicated gene pairs might undergo different evolutionary pressures and diverge at varying periods.

\section{Expression levels of $D c S D G s$ in response to environmental stresses}

D. catenatum is an epiphytic orchid plant that grows on trunks and cliffs and often experiences diverse environmental stresses, such as drought, cold, and high temperature. To detect the responses of DcSDG genes to drought stress, the expression profiles of DcSDGs were assessed by analyzing the RNA-seq data from the leaves under different drought treatments [99] (Fig. 7 and Additional file 5). In brief, the seedlings were irrigated on the 1st day, and kept unwatered from the 2nd day to the 7th day, and recovered on the 8th day. Leaves were sampled at both 06:30 and 18:30 on the 2nd (DR5 and DR8), 7th (DR6 and DR10), and 9th (DR7 and DR15) days, respectively, and at 18:30 on the 8th day (DR11). The results showed that one-week of drought stress notably repressed the expressions of DcCLF, DcASHR3, $D c S U V R 3$, and DcSUVR14c, but obviously induced the expression of DcATXR5b, DcATXR4, and DcSDG49 when sampling at both dawn and dusk. Subsequently, rewatering restored the expression levels of DcASHR3, DcSUVR3, DcATXR5b, DcATXR4, and DcSDG49.

To explore the possible roles of SDG proteins in response to cold stress, we evaluated the expression levels of DcSDGs through analyzing the raw RNA-seq reads from the leaves of $D$. catenatum seedlings treated at $20^{\circ} \mathrm{C}$ (control) and $0{ }^{\circ} \mathrm{C}$ for $20 \mathrm{~h}$, respectively [43] (Fig. 8 and Additional file 6). Data revealed that $32 \%$ of DcSDG genes (14) showed transcription change in response to cold stress. For example, genes with upregulated expression consisted of DcASHH1 (II), DcATX3b (III), DcSUVH4 (V), DcSUVH5a (V), DcSUVH5b (V), DcSDG45 (VII), and DcSDG51 (VII), whereas genes with deregulated expressions included DcATXR5a (IV), DcATXR5b (IV), DcSUVR14a (V), DcASHR1 (VI), DcASHR2 (VI), DcATXR2 (VI), and DcSDG50 (VII). The expression levels of DcSUVH5a, 


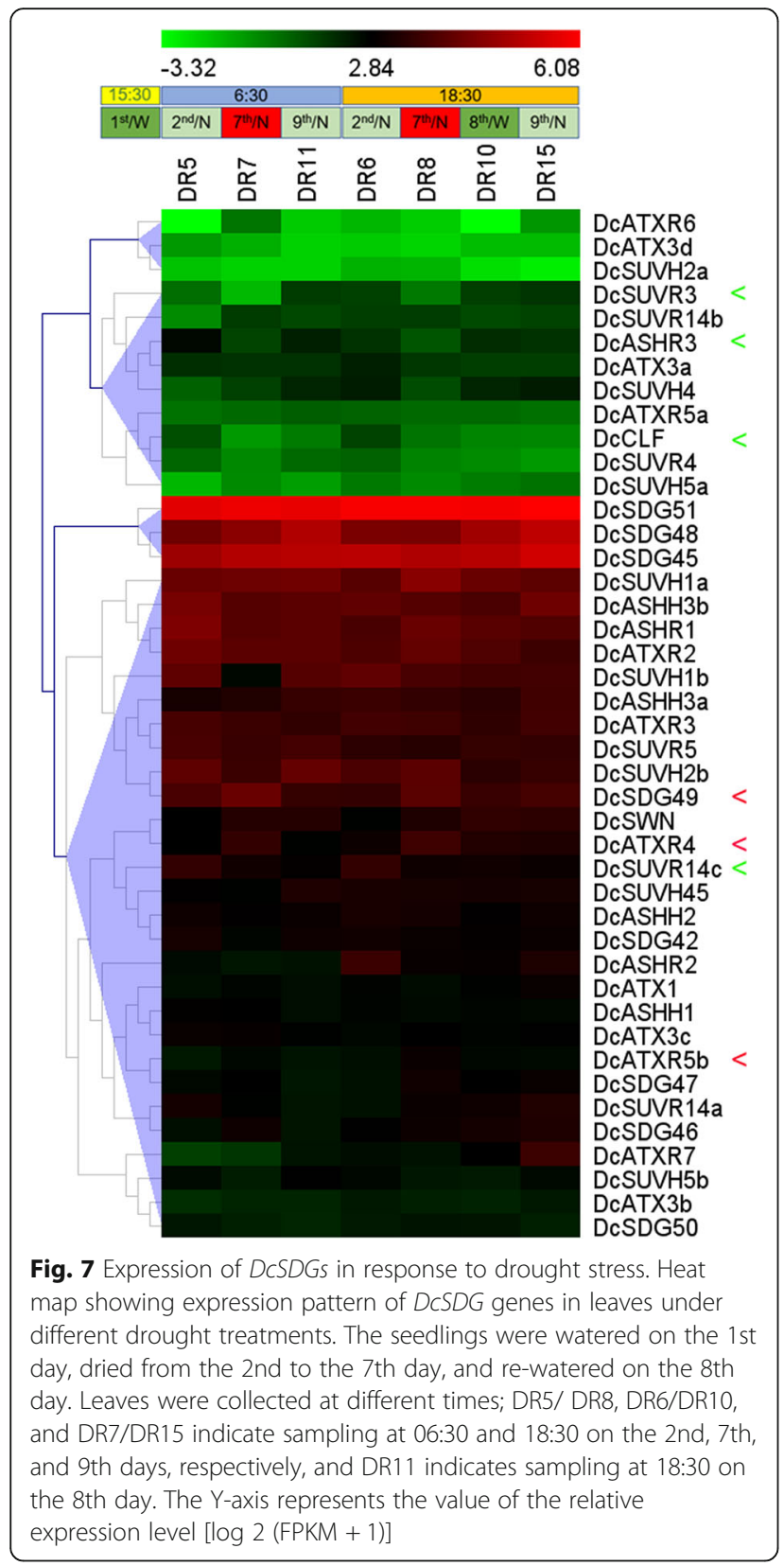

DcATXR5a, DcASHR2 and DcSUVR14a (fold change $>2$ or $<0.5$ ) are significantly influenced by cold.

To further understand the roles of DcSDG proteins in response to high temperature $\left(35^{\circ} \mathrm{C}\right)$ stress, the expression profiles of SDG genes in the leaves of $D$. catenatum seedlings were examined by quantitative reverse-transcription-polymerase chain reaction (RT-qPCR) (Fig. 9). The results show the diverse expression patterns of $D c S D G$ genes during heat shock treatment. At $3 \mathrm{~h}$ after treatment (HAT), the number of upregulated genes (10) was slightly higher than that of downregulated genes (7). At 6 HAT, more DcSDG genes were induced (15 upregulated genes versus 10 downregulated genes). At 12

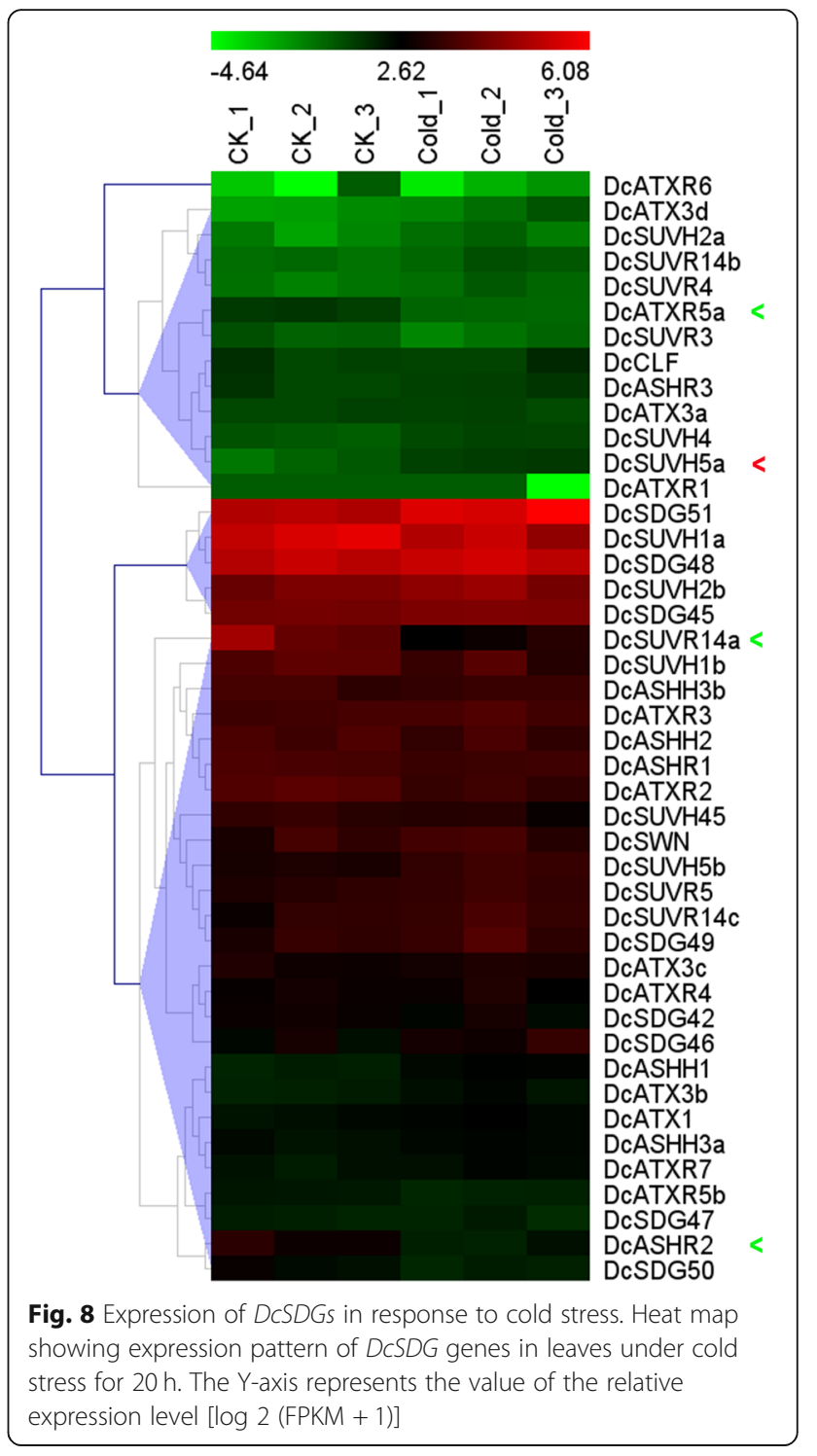

HAT, the number of upregulated genes (27) was evidently higher than that of downregulated genes (3). Of the genes examined upon exposure to heat shock, three Class II genes (DcASHH3a/3b and DcATX3a), five Class $\mathrm{V}$ genes (DcSUVH2a/2b, DcSUR14b/14c, and DcSUVR3), two Class VI genes (DcATXR1 and DcASHR1), two Class VII genes (DcSDG45/48), and one Class M gene $D c A T X R 3$ were distinguished from the corresponding control in at least at one time point $(P<0.05$, Fig. 9).

\section{Discussion}

\section{Characterization and classification of SDG proteins in $D$. catenatum}

D. catenatum shows extensive application value in the food service industry, pharmaceutical, cosmetics, health products, and ornamental horticulture in China. The recent successful genome sequencing of $D$. catenatum 


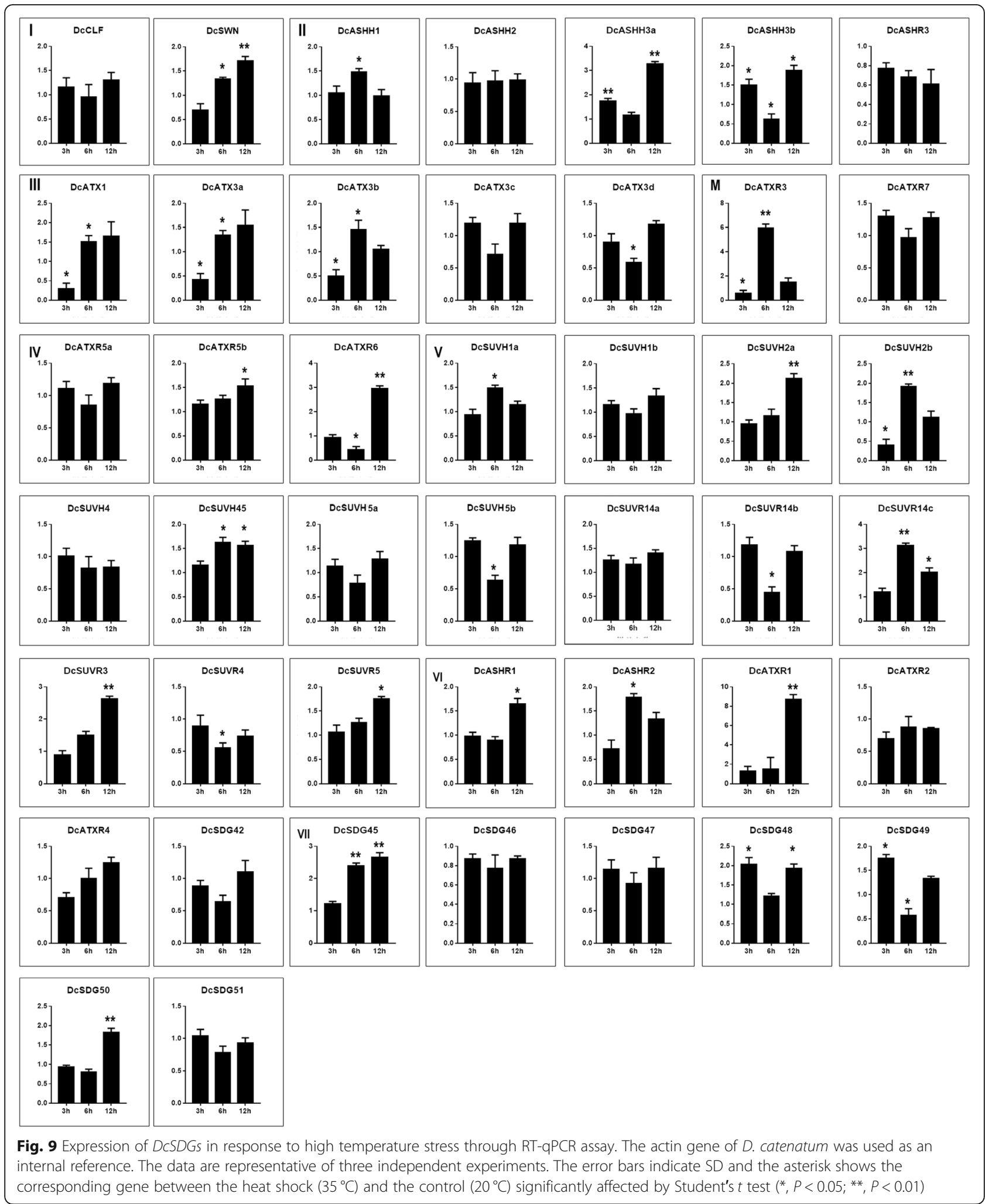

associated with its unique developmental and living features promoted its use as a model orchid plant with considerable theoretical relevance [100]. In this study, 44
SDG proteins in D. catenatum was identified and divided into eight classes: Class-I (H3K27me2/3), Class-II (H3K36), Class-III (H3K4me2/3), Class-M (H3K4me), 
Class-IV (H3K27me1), Class-V (H3K9me), Class-VI/S-ET (undefined), Class-VII/ RBCMT (non-histone Rubisco).

To date, the understanding of Class VI and VII is highly limited. Class VI includes six clades (Additional file 7), whose members feature a long S-ET domain interrupted by a Zf-MYND domain and have not been functionally characterized in plants. In mammalian ASHR1 homologs, SET And MYND Domain Containing 3 (SMYD3) may methylate histones H3K4 and H4K5, whereas SMYD2 can dimethylate H3K36 and repress gene transcription [101-103]. SMYD proteins also possess non-histone substrates, such as SMYD2 for p53 and estrogen receptor $\alpha$ and SMYD3 for VEGFR1 and MAP 3 K2, in the nucleus and cytoplasm [104-107]. Class VII consists of nine clades (Additional file 8), whose members are characterized by an additional Rubisco substrate-binding (Rubis-subs-bind) domain and conserved in plants and animals. In flowering plants, chloroplast-localized Rubisco large subunit Nmethyltransferase (LSMT) performs the conserved and ancient functions to methylate the Rubisco small subunit and fructose-1,6-bisphosphate aldolase (FBA). Moreover, this enzyme evolved an extra novel role to catalyze the K14 trimethylation of Rubisco large subunit in Fabaceae, Cucurbitaceae, and Rosaceae [108, 109]. Based on the strict correlation between the presence of the His-Ala/ Pro-Trp triad motif and the Rubisco methylation status [108], LSMTs in D. catenatum and the other three examined species only retained the ancestral function due to the absence of this triad motif. In animal, Class VII homo$\log$ SETD3 with additional Rubis-subs-bind domain exhibits a H3K36 methyltransferase activity [110]. Therefore, the members of Class VI and VII in plants may be involved in the methylation of both histone and non-histone proteins; such assumption is beyond the previous expectation.

\section{Evolution and function divergence of SDG proteins}

Gene duplication, as a critical driving force, provides an extra copy of genetic material to tolerate random mutations to survive the natural selection and create new species during evolution. Gene duplication, including tandem duplication and polyploidy (whole genome duplication, WGD), considerably contributes to the formation of gene families [24], such as the SDG family in D. catenatum. D. catenatum has undergone at least four rounds of WGD events, including two ancient WGDs before $(\zeta)$ and after $(\varepsilon)$ the angiosperm split from gymnosperm, a $\tau$ WGD shared by most monocots and a recent WGD specific to the Orchidaceae lineage $[98,111]$. Duplicate genes usually undergo three evolutionary fates, nonfunctionalization with silencing function, neofunctionalization with novel function, and subfunctionalization with partial function [112]. D. catenatum contains six pairs of duplicated $D c S D G$ genes. In $D c S U V H 2 a / 2 b$ pairs, $D c S U V H 2 a$ was unexpressed in all examined tissues, implying that neofunctionalization might have occurred. DcASHH3a/3b, $D c A T X 3 b / 3 c, D c A T X R 5 a / 5 b$ and DcSUVR14b/14c pairs displayed similar expression patterns, indicating that they might have experienced subfunctionalization. DcSUVH5a/ $5 b$ pairs exhibited differential expression profiles in different tissues and organs, indicating that novel expression specificity and function have developed.

\section{Involvement of SDG proteins in plant development programs and environmental stress responses}

SDG proteins associated with the corresponding histone methylations can output precise developmental instructions through diverse mechanisms. (1) Different SDG proteins show similar catalytic specificity, but act on distinct sets of genes. As the writers of H3K4 methylation, ATX3/4/5 have different targets from ATXR3/SDG2 [66]. (2) Some SDG members are involved in specific conserved complexes. Class I E(z) homologs (CLF, SWN and MEA), together with MSI1, FIE, and $\mathrm{Su}(\mathrm{z}) 12$ homologs (FIS2, EMF2 and VRN2) constitute different PRC2 complexes, functioning in distinct developmental phases [113]. (3) Specific SDG proteins can interplay with other types of epigenetic regulators. SUVH4/5/6 interacts with the histone deacetylase HDA6 to silence a subset of transposons through histone $\mathrm{H} 3 \mathrm{~K} 9$ methylation and $\mathrm{H} 3$ deacetylation [114]. Further in-depth molecular dissection of SDG members in $D$. catenatum with specific developmental and living modes will enrich the action mechanisms of the SDG gene family.

Histone methylation established by SDG proteins is widely involved in responses to environmental stresses and pathogen challenges [27, 33, 35-38]. Studies have reported that drought stress can cause global changes of histone H3K4 methylation patterns in Arabidopsis and rice $[37,38]$. Class III member ATX1 is implicated in drought stress response via both ABA-dependent and -independent pathways in Arabidopsis [35, 36]. Here we observed that the dynamic expression changes of DcASHR3 (Class II), DcSUVR3 (V), DcATXR5b (V), $D c A T X R 4$ (VI), and DcSDG49 (VII) were closely associated with drought-rewatering treatment, indicating that methylations of $\mathrm{H} 3 \mathrm{~K} 36$ and $\mathrm{H} 3 \mathrm{~K} 9$ are also involved in drought response. H3K36me3 and H3K27me3 have been proven to play antagonistic roles in the cold-induced epigenetic switch at the Arabidopsis FLOWERING LOCUS C (FLC) locus [115]. In D. catenatum, we identified six significant cold-responsive DcSDG genes, including DcASHH1 (Class II), DcATX3b/3d (III), DcATXR5a/ $5 b$ (Class M), DcSUVH5a/5b and DcSUVR14a/3 (V) (Fig. 8). The results indicate diverse histone methylation marks with specific DcSDG proteins that perform certain roles during cold treatment. It will be intriguing to further investigate their direct targets by high-throughput 
ChIP-seq method combined with excellent commercial antibodies against various histone methylation marks. Recently, Huang et al. [24] thoroughly identified cotton SDG genes and noted that the expressions of most of these genes decreased under high-temperature conditions. In this study, $61 \%$ of DcSDG genes showed response to heat shock, but the number of upregulated genes was considerably higher than that of downregulated ones. This finding may be related to the particularly epiphytic lifestyle and crassulacean acid metabolism pathway in D. catenatum.

\section{Conclusions}

In this study, we identified 44. SDG proteins in D. catenatum and 42 in its close relative $P$. equestris, and replenished three other SDG members (Os01g65730/OsSET44, Os01g74500/OsSET45, and Os06g03676/OsSET46) into the previous rice SDG gene family (43 members). Based on the phylogenetic relationship and substrate specificity, these genes were divided into eight classes by using well-characterized Arabidopsis SDG members as references. In addition, we analyzed the expression profiles of $D$. catenatum SDG genes in different tissues and organs and their responses to diverse environmental stresses. Our findings provide comprehensive information on the classification and expression profiles on $D$. catenatum $S D G$ genes, and will lay the foundation for the functional characterization of the $S D G$ gene family in orchids.

\section{Methods}

Identification of SDG gene family in $D$. catenatum and $P$. equestris

All the SDG sequences including genomic DNAs, CDS and proteins in Oryza sativa and Arabidopsis thaliana were retrieved from the plant genomics resource Phytozome v12 (http://phytozome.jgi.doe.gov/pz/portal.html). Of these, the protein sequences were used as queries to search homologs of $D$. catenatum and $P$. equestris against NCBI database using BLASTp tool. All the hits were further confirmed by the existence of the signature SET domain detected using on-line biosofts PROSITE (http://prosite.expasy.org/), SMART (http:// smart.emblheidelberg.de/) and PFam (http://pfam.xfam.org/search).

\section{Analysis of gene structure, domain architecture and phylogenetic relationship}

The gene structure including the intron-exon distribution pattern was reconstructed by Gene Structure Display Server GSDS 2.0 (http://gsds.cbi.pku.edu.cn/) [116]. The domain organization was analyzed using SMART and Pfam databases. Phylogenetic analysis was performed using MEGA7 [117]. The full-length amino acid sequences of SDG proteins were used for constructing neighbor-joining (NJ) trees with the following settings: pairwise deletion option for gaps/missing data treatment; p-distance method for Substitution model; and bootstrap test of 1000 replicates for evaluation of internal branch reliability.

\section{In silico expression profiling of DcSDG genes}

For the tissue and organ expression profiling of DcSDG genes, The raw RNA-seq data of leaf (SRR4431601), root (SRX2938667), Green root tip (SRR4431599), white part of root (SRR4431598), stem (SRR4431600), flower bud (SRR4431603), sepal (SRR4431597), labellum (SRR4431602), pollinia (SRR5722145) and gynostemium (SRR4431596) in an individual of wild $D$. catenatum were downloaded from the NCBI Sequence Read Archive (SRA) provided by Zhang et al [98]. For drought stress and stress removal experiment in 8-month-old D. catenatum plants [99], irrigation was performed on the 1st day, omitted from the 2nd to the 7th day, and resumed on the 8th day, watering every 2 days at 15:30. Consequently, the raw RNA-seq reads were obtained from the leaves that were harvested at both $06: 30$ and 18:30 on the 2nd [DR5 (NCBI: SRR7223299) and DR8 (SRR7223300)], 7th [DR6 (SRR7223298) and DR10 (SRR7223296)], and 9th [DR7 (SRR7223301) and DR15 (SRR7223297)] days, respectively, and at 18:30 on the 8th day [DR11 (SRR7223295)]. For the expression analysis of $D c S D G$ genes in response to cold stress, the raw RNA-seq reads of leaves under $20^{\circ} \mathrm{C}$ control condition (SRR3210630, SRR3210635 and SRR3210636) and $0{ }^{\circ} \mathrm{C}$ cold treatment for $20 \mathrm{~h}$ (SRR3210613, SRR3210621 and SRR3210626) were obtained from NCBI provided by Wu et al [43]. Reads of all the samples were aligned to the NCBI Dendrobium reference genome using HISAT package [118] The mapped reads of each sample were assembled using StringTie [119]. Then, all transcriptomes from samples were merged to reconstruct a comprehensive transcriptome using perl scripts. After the final transcriptome was generated, StringTie and edgeR was used to estimate the expression levels of all transcripts. StringTie was used to perform expression level for mRNAs by calculating FPKM. DcSDG genes were selected and differentially expressed genes were defined with $\log 2$ (fold change) $>1$ or $<-1$ and with statistical significance $(p$ value $<0.05$ ) by $\mathrm{R}$ package. Heatmap was generated using TIGR MultiExperiment Viewer (MeV4.9) software [120].

\section{Plant material and heat shock treatment}

D. catenatum cultivar "Jingpin NO. 1" (Breed NO. Zhe R-SV-DO-015-2014) was from the State Key Laboratory of Subtropical Silviculture in Zhejiang Province, China. D. catenatum was grown in greenhouse at $20^{\circ} \mathrm{C}$ under a $12 \mathrm{~h}$ light $/ 12 \mathrm{~h}$ dark regime. 1-year-old seedlings were treated at $35^{\circ} \mathrm{C}$ heat shock for indicated time $(3 \mathrm{~h}, 6 \mathrm{~h}$ and $12 \mathrm{~h}$ ) in a temperature-controlled incubator, compared with the mock plants at $20^{\circ} \mathrm{C}$. Then the leaves 
were harvested, snap frozen in liquid nitrogen and stored at $-70^{\circ} \mathrm{C}$ for further expression analysis.

\section{Real-time quantitative RT-PCR (RT-qPCR)}

Total RNA was extracted from the leaves using TRIzol reagent (Invitrogen, USA) followed by RNase-free DNase I treatment. First strand cDNA synthesis was performed via PrimerScript RT Enzyme Mix I kit (TaKaRa, Japan), according to the manufacturer's instructions. RT-qPCR reaction mixture $(10 \mu \mathrm{l})$ was prepared according to the manual of SYBR ${ }^{\circ}$ Premix Ex Taq ${ }^{\mathrm{Tm}}$ II (Tli RNaseH Plus) kit (TaKaRa, Japan). Then the reaction was carried out on CFX96 Touch $^{\text {TM }}$ Real-Time PCR Detection System (BIO-RAD, USA) in three technical replicates for each biological triplicate using the primers listed in Additional file 9. The reaction condition was set as the following temperature profile: $94^{\circ} \mathrm{C}$ for $3 \mathrm{~m}, 40$ cycles of $94{ }^{\circ} \mathrm{C}$ for $20 \mathrm{~s}, 60^{\circ} \mathrm{C}$ for 20 s, $72{ }^{\circ} \mathrm{C}$ for 20 s. The constitutive DcACTIN was used as the reference gene. The expression value of each gene tested was normalized with the internal reference gene, and the relative expression level was calculated with $2^{-\Delta \Delta \mathrm{CT}}$ method [121].

\section{Supplementary information}

Supplementary information accompanies this paper at https://doi.org/10. 1186/s12870-020-2244-6.

Additional file 1. SDG protein sequences in Arabidopsis and rice retrieved from Phytozome 12 database.

Additional file 2. Identification and classification of SDG genes in P. equestris. Sequences and information of $P$. equestris SDG genes and proteins came from NCBI database (https://www.ncbi.nlm.nih.gov/)

Additional file 3. Expression data of DcSDG genes from different tissues and organs in D. catenatum. The FPKM values of DCSDG genes in different tissues and organs was used for expression analysis in Fig. 6. Lf: leaf, Ro: root, Gr: green root tip, Wr: white part of root, St: stem, Fb: flower bud, Se: sepal, Lb: labellum, Po: pollinia, and Gs, gynostemium.

Additional file 4. Expression patterns of duplicated SDG gene pairs. The FPKM values of the duplicated DCSDG genes in different tissues and organs was used for comparison. Lf: leaf, Ro: root, Gr: green root tip, Wr: white part of root, St: stem, Fb: flower bud, Se: sepal, Lb: labellum, Po: pollinia, and Gs, gynostemium.

Additional file 5. Expression data of DcSDG genes from different drought treatments. The FPKM values of DCSDG genes in leaves under different drought treatments were used for expression analysis in Fig. 7 The seedlings were watered on the 1st day, dried from the 2 nd to the 7th day, and re-watered on the 8th day. Leaves were collected at different times; DR5/ DR8, DR6/DR10, and DR7/DR15 indicate sampling at 06:30 and 18:30 on the 2nd, 7th, and 9th days, respectively, and DR11 indicates sampling at 18:30 on the 8th day.

Additional file 6. Expression data of DCSDG genes in the absence and presence of cold treatment. The FPKM values of DcSDGs genes in leaves under cold stress $/ 20^{\circ} \mathrm{C}$ (control) for $20 \mathrm{~h}$ were used for expression analysis in Fig. 8

Additional file 7. Domain organization and gene structure of the classVI DcSDGs. The NJ tree was generated using MEGA7 with parameter settings as Fig. 1 based on full-length amino acid sequences of Class-VI SDGs in D. catenatum, $P$. equestris, Arabidopsis and rice. The number along the tree branch indicates bootstrap value. Different conserved protein domains are colored as indicated. Gene structures of SDGs in each species were indicated in distinct colors. The solid boxes represent exons and black lines represent introns.

Additional file 8. Domain organization and gene structure of the classVII DCSDGs. The NJ tree was generated using MEGA7 with parameter settings as Fig. 1 based on full-length amino acid sequences of Class-VII SDGs in D. catenatum, $P$. equestris, Arabidopsis and rice. The number along the tree branch indicates bootstrap value. Different conserved protein domains are colored as indicated. Gene structures of SDGs in each species were indicated in distinct colors. The solid boxes represent exons and black lines represent introns.

Additional file 9. Primers used for expression analysis of heat shock treatment in this study.

\section{Abbreviations}

ABA: Abscisic acid; ATX1: ARABIDOPSIS TRITHORAX-LIKE PROTEIN1; ATXR3: ARABIDOPSIS TRITHORAX RELATED 3; ChIP-Seq: Chromatin immunoprecipitation-based sequencing; CLF: CURLY LEAF; E(Z): Zeste; FBA: Fructose-1,6-bisphosphate aldolase; FLC: FLOWERING LOCUS C; HAT: Hour after treatment; HKMTase: Histone lysine methyltransferase; JA: Jasmonic acid; KYP: KRYPTONITE; MEA: MEAEA; NJ: Neighbor-joining; PRC2: Polycomb Repressive Complex 2; RBCMT: Ribulose-1,5-bisphosphate carboxylase/oxygenase (Rubisco) methyltransferase; RdDM: RNA-directed DNA methylation; RT-qPCR: Real-time quantitative polymerase chain reaction; Rubis-subs-bind: Rubisco substrate-binding; SA: Salicylic acid; SDG: SET DOMAIN GROUP; SET: Su (var), E(z), and Trithorax; SMYD3: SET and MYND domain containing 3; SRA: SET- and RING-ASSOCIATED; Su (var): Suppressor of variegation; SWN: SWINGER; Trx: Trithorax; WGD: Whole genome duplication

\section{Acknowledgements}

We thank the manuscript editing provided by the professional editing company EnPapers (http://www.enpapers.com/).

\section{Authors' contributions}

DHC and JPS planned and designed the research. HLQ performed the experiments. DHC, HLQ, YH and LZ analyzed the data. DHC and JPS wrote the article. All the authors approved the manuscript.

\section{Funding}

This work was funded by National Key R\&D Program of China (2017YFC1702201) focusing on wild imitation cultivation and stress response mechanisms of Dendrobium, National Natural Science Foundation of China (31870310) focusing on epigenetic mechanism of Dendrobium epiphytic lifestyle, Scientific R\&D Foundation for Talent Start-up Project of Zhejiang A\&F University (2017FR035) focusing on the functional dissection of histone methylation in Dendrobium, and the State Key Laboratory of Subtropical Silviculture (ZY20180206) focusing on metabolic mechanism of environmental fitness in Dendrobium. The funding agencies were not involved in the design of the study and collection, analysis, and interpretation of data and in writing the manuscript.

\section{Availability of data and materials}

All data generated or analyzed during this study are included in this published article and its Additional files. The datasets generated and analyzed during the current study are available from the corresponding author on reasonable request.

\section{Ethics approval and consent to participate}

The D. catenatum used in this study is a commercial cultivar "Jing in NO. 1", which was cultivated by Prof Jinping Si (Zhejiang A\&F University), was authorized by Zhejiang Province with Breed NO. Zhe R-SV-DO-015-2014. It does not require ethical approval.

\section{Consent for publication}

Not applicable.

Competing interests

The authors declare that they have no competing interests. 


\section{Author details}

'State Key Laboratory of Subtropical Silviculture, SFGA Engineering Research Center for Dendrobium catenatum (D. officinale), Zhejiang A\&F University, Lin'an, Hangzhou 311300, Zhejiang, China. ${ }^{2}$ Key Laboratory of Education Department of Hunan Province on Plant Genetics and Molecular Biology, Hunan Agricultural University, Changsha 410128, China.

Received: 3 September 2019 Accepted: 13 January 2020

\section{Published online: 28 January 2020}

\section{References}

1. Goldberg AD, Allis CD, Bernstein E. Epigenetics: a landscape takes shape. Cell. 2007;128(4):635-8.

2. Huang H, Sabari BR, Garcia BA, Allis CD, Zhao Y. SnapShot: histone modifications. Cell. 2014;159(2):458.

3. Lawrence M, Daujat S, Schneider R. Lateral thinking: how histone modifications regulate gene expression. Trends in genetics: TIG. 2016;32(1): 42-56.

4. Jenuwein T, Allis CD. Translating the histone code. Science. 2001;293(5532): 1074-80.

5. Strahl BD, Allis CD. The language of covalent histone modifications. Nature. 2000:403(6765):41-5.

6. Liu C, Lu F, Cui X, Cao X. Histone methylation in higher plants. Annu Rev Plant Biol. 2010;61:395-420.

7. Tschiersch B, Hofmann A, Krauss V, Dorn R, Korge G, Reuter G. The protein encoded by the Drosophila position-effect variegation suppressor gene Su (var)3-9 combines domains of antagonistic regulators of homeotic gene complexes. EMBO J. 1994;13(16):3822-31.

8. Feng $\mathrm{Q}$, Wang $\mathrm{H}, \mathrm{Ng} \mathrm{HH}$, Erdjument-Bromage $\mathrm{H}$, Tempst P, Struhl $\mathrm{K}$, Zhang Y. Methylation of H3-lysine 79 is mediated by a new family of HMTases without a SET domain. Current biology : CB. 2002;12(12):1052-8.

9. Zhang Y, Reinberg D. Transcription regulation by histone methylation: interplay between different covalent modifications of the core histone tails. Genes Dev. 2001;15(18):2343-60.

10. Ng DW, Wang T, Chandrasekharan MB, Aramayo R, Kertbundit S, Hall TC Plant SET domain-containing proteins: structure, function and regulation. Biochim Biophys Acta. 2007;1769(5-6):316-29.

11. Huang Y, Liu C, Shen WH, Ruan Y. Phylogenetic analysis and classification of the Brassica rapa SET-domain protein family. BMC Plant Biol. 2011;11:175.

12. Mujtaba S, Manzur KL, Gurnon JR, Kang M, Van Etten JL, Zhou MM. Epigenetic transcriptional repression of cellular genes by a viral SET protein. Nat Cell Biol. 2008;10(9):1114-22.

13. Alvarez-Venegas R, Sadder M, Tikhonov A, Avramova Z. Origin of the bacterial SET domain genes: vertical or horizontal? Mol Biol Evol. 2007;24(2): 482-97.

14. Aravind L, lyer LM. Provenance of SET-domain histone methyltransferases through duplication of a simple structural unit. Cell Cycle. 2003;2(4):369-76.

15. Stephens RS, Kalman S, Lammel C, Fan J, Marathe R, Aravind L, Mitchell W, Olinger L, Tatusov RL, Zhao Q, et al. Genome sequence of an obligate intracellular pathogen of humans: chlamydia trachomatis. Science. 1998; 282(5389):754-9.

16. Alvarez-Venegas R. Bacterial SET domain proteins and their role in eukaryotic chromatin modification. Front Genet. 2014;5:65.

17. Pontvianne F, Blevins T, Pikaard CS. Arabidopsis histone lysine Methyltransferases. Adv Bot Res. 2010;53:1-22

18. Aquea F, Vega A, Timmermann T, Poupin MJ, Arce-Johnson P. Genomewide analysis of the SET DOMAIN GROUP family in grapevine. Plant Cell Rep. 2011;30(6):1087-97.

19. Lei L, Zhou SL, Ma H, Zhang LS. Expansion and diversification of the SET domain gene family following whole-genome duplications in Populus trichocarpa. BMC Evol Biol. 2012;12:51.

20. Qian Y, Xi Y, Cheng B, Zhu S. Genome-wide identification and expression profiling of DNA methyltransferase gene family in maize. Plant Cell Rep. 2014;33(10):1661-72

21. Lu Z, Huang X, Ouyang Y, Yao J. Genome-wide identification, phylogenetic and co-expression analysis of OsSET gene family in rice. PLoS One. 2013; 8(6):e65426.

22. Aiese Cigliano R, Sanseverino W, Cremona G, Ercolano MR, Conicella C, Consiglio FM. Genome-wide analysis of histone modifiers in tomato: gaining an insight into their developmental roles. BMC Genomics. 2013; 14:57.
23. Xu J, Xu H, Liu Y, Wang X, Xu Q, Deng X. Genome-wide identification of sweet orange (Citrus sinensis) histone modification gene families and their expression analysis during the fruit development and fruit-blue mold infection process. Front Plant Sci. 2015;6:607.

24. Huang Y, Mo Y, Chen P, Yuan X, Meng F, Zhu S, Liu Z. Identification of SET domain-containing proteins in Gossypium raimondii and their response to high temperature stress. Sci Rep. 2016;6:32729.

25. Yadav CB, Muthamilarasan M, Dangi A, Shweta S, Prasad M. Comprehensive analysis of SET domain gene family in foxtail millet identifies the putative role of SiSET14 in abiotic stress tolerance. Sci Rep. 2016;6:32621.

26. Peng M, Ying P, Liu X, Li C, Xia R, Li J, Zhao M. Genome-wide identification of histone modifiers and their expression patterns during fruit abscission in Litchi. Front Plant Sci. 2017:8:639.

27. Berr A, McCallum EJ, Alioua A, Heintz D, Heitz T, Shen WH. Arabidopsis histone methyltransferase SET DOMAIN GROUP8 mediates induction of the jasmonate/ethylene pathway genes in plant defense response to necrotrophic fungi. Plant Physiol. 2010;154(3):1403-14.

28. Berr A, McCallum EJ, Menard R, Meyer D, Fuchs J, Dong A, Shen WH. Arabidopsis SET DOMAIN GROUP2 is required for H3K4 trimethylation and is crucial for both sporophyte and gametophyte development. Plant Cell. 2010:22(10):3232-48.

29. Cazzonelli Cl, Cuttriss AJ, Cossetto SB, Pye W, Crisp P, Whelan J, Finnegan EJ, Turnbull C, Pogson BJ. Regulation of carotenoid composition and shoot branching in Arabidopsis by a chromatin modifying histone methyltransferase, SDG8. Plant Cell. 2009;21(1):39-53.

30. Cazzonelli Cl, Nisar N, Roberts AC, Murray KD, Borevitz JO, Pogson BJ. A chromatin modifying enzyme, SDG8, is involved in morphological, gene expression, and epigenetic responses to mechanical stimulation. Front Plant Sci. 2014;5:533.

31. Dong G, Ma DP, Li J. The histone methyltransferase SDG8 regulates shoot branching in Arabidopsis. Biochem Biophys Res Commun. 2008;373(4):65964.

32. Sui P, Jin J, Ye S, Mu C, Gao J, Feng H, Shen WH, Yu Y, Dong A. H3K36 methylation is critical for brassinosteroid-regulated plant growth and development in rice. Plant J. 2012;70(2):340-7.

33. Palma K, Thorgrimsen S, Malinovsky FG, Fiil BK, Nielsen HB, Brodersen $P$, Hofius D, Petersen M, Mundy J. Autoimmunity in Arabidopsis acd11 is mediated by epigenetic regulation of an immune receptor. PLoS Pathog. 2010;6(10):e1001137.

34. Alvarez-Venegas R, Abdallat AA, Guo M, Alfano JR, Avramova Z. Epigenetic control of a transcription factor at the cross section of two antagonistic pathways. Epigenetics. 2007;2(2):106-13.

35. Ding Y, Lapko H, Ndamukong I, Xia Y, Al-Abdallat A, Lalithambika S, Sadder M, Saleh A, Fromm M, Riethoven JJ, et al. The Arabidopsis chromatin modifier ATX1, the myotubularin-like AtMTM and the response to drought. Plant Signal Behav. 2009;4(11):1049-58.

36. Ding Y, Avramova Z, Fromm M. The Arabidopsis trithorax-like factor ATX1 functions in dehydration stress responses via ABA-dependent and ABAindependent pathways. Plant J. 2011;66(5):735-44.

37. van Dijk K, Ding Y, Malkaram S, Riethoven JJ, Liu R, Yang J, Laczko P, Chen $\mathrm{H}$, Xia $\mathrm{Y}$, Ladunga I, et al. Dynamic changes in genome-wide histone $\mathrm{H3}$ lysine 4 methylation patterns in response to dehydration stress in Arabidopsis thaliana. BMC Plant Biol. 2010;10:238.

38. Zong W, Zhong X, You J, Xiong L. Genome-wide profiling of histone H3K4tri-methylation and gene expression in rice under drought stress. Plant Mol Biol. 2013;81(1-2):175-88.

39. Kwon CS, Lee D, Choi G, Chung WI. Histone occupancy-dependent and -independent removal of H3K27 trimethylation at cold-responsive genes in Arabidopsis. Plant J. 2009:60(1):112-21.

40. Yan L, Wang X, Liu H, Tian Y, Lian J, Yang R, Hao S, Wang X, Yang S, Li Q, et al. The genome of Dendrobium officinale illuminates the biology of the important traditional Chinese orchid herb. Mol Plant. 2015;8(6):922-34.

41. Tang H, Zhao T, Sheng Y, Zheng T, Fu L, Zhang Y. Dendrobium officinale Kimura et Migo: a review on its Ethnopharmacology, Phytochemistry, pharmacology, and industrialization. Evid Based Complement Altern Med. 2017:2017:7436259.

42. Ng TB, Liu J, Wong JH, Ye X, Wing Sze SC, Tong Y, Zhang KY. Review of research on Dendrobium, a prized folk medicine. Appl Microbiol Biotechnol. 2012;93(5):1795-803

43. Wu ZG, Jiang W, Chen SL, Mantri N, Tao ZM, Jiang CX. Insights from the Cold Transcriptome and Metabolome of Dendrobium officinale: Global 
Reprogramming of Metabolic and Gene Regulation Networks during Cold Acclimation. Front Plant Sci. 2016;7:1653.

44. Zheng $B$, Chen X. Dynamics of histone $\mathrm{H} 3$ lysine 27 trimethylation in plant development. Curr Opin Plant Biol. 2011;14(2):123-9.

45. Goodrich J, Puangsomlee P, Martin M, Long D, Meyerowitz EM, Coupland G. A Polycomb-group gene regulates homeotic gene expression in Arabidopsis. Nature. 1997;386(6620):44-51.

46. Grossniklaus U, Vielle-Calzada JP, Hoeppner MA, Gagliano WB. Maternal control of embryogenesis by MEDEA, a polycomb group gene in Arabidopsis. Science. 1998;280(5362):446-50.

47. Kiyosue T, Ohad N, Yadegari R, Hannon M, Dinneny J, Wells D, Katz A, Margossian L, Harada JJ, Goldberg RB, et al. Control of fertilizationindependent endosperm development by the MEDEA polycomb gene in Arabidopsis. Proc Natl Acad Sci U S A. 1999;96(7):4186-91.

48. Liu X, Zhou C, Zhao Y, Zhou S, Wang W, Zhou DX. The rice enhancer of zeste $[E(Z)]$ genes SDG711 and SDG718 are respectively involved in long day and short day signaling to mediate the accurate photoperiod control of flowering time. Front Plant Sci. 2014;5:591.

49. Springer NM, Napoli CA, Selinger DA, Pandey R, Cone KC, Chandler VL, Kaeppler HF, Kaeppler SM. Comparative analysis of SET domain proteins in maize and Arabidopsis reveals multiple duplications preceding the divergence of monocots and dicots. Plant Physiol. 2003;132(2):907-25.

50. Lee J, Yun JY, Zhao W, Shen WH, Amasino RM. A methyltransferase required for proper timing of the vernalization response in Arabidopsis. Proc Natl Acad Sci U S A. 2015;112(7):2269-74.

51. Sahr T, Adam T, Fizames C, Maurel C, Santoni V. O-carboxyl- and Nmethyltransferases active on plant aquaporins. Plant Cell Physiol. 2010; 51(12):2092-104.

52. Sun C, Fang J, Zhao T, Xu B, Zhang F, Liu L, Tang J, Zhang G, Deng X, Chen $F$, et al. The histone methyltransferase SDG724 mediates H3K36me2/3 deposition at MADS50 and RFT1 and promotes flowering in rice. Plant Cell. 2012:24(8):3235-47.

53. Cartagena JA, Matsunaga S, Seki M, Kurihara D, Yokoyama M, Shinozaki K, Fujimoto S, Azumi Y, Uchiyama S, Fukui K. The Arabidopsis SDG4 contributes to the regulation of pollen tube growth by methylation of histone H3 lysines 4 and 36 in mature pollen. Dev Biol. 2008;315(2):355-68.

54. Thorstensen T, Grini PE, Mercy IS, Alm V, Erdal S, Aasland R, Aalen RB. The Arabidopsis SET-domain protein ASHR3 is involved in stamen development and interacts with the $\mathrm{BHLH}$ transcription factor ABORTED MICROSPORES (AMS). Plant Mol Biol. 2008;66(1-2):47-59.

55. Kumpf R, Thorstensen T, Rahman MA, Heyman J, Nenseth HZ, Lammens T, Herrmann U, Swarup R, Veiseth SV, Emberland G, et al. The ASH1-RELATED3 SET-domain protein controls cell division competence of the meristem and the quiescent center of the Arabidopsis primary root. Plant Physiol. 2014; 166(2):632-43.

56. Berr A, Shafiq S, Pinon V, Dong A, Shen WH. The trxG family histone methyltransferase SET DOMAIN GROUP 26 promotes flowering via a distinctive genetic pathway. Plant J. 2015;81(2):316-28.

57. Xu L, Zhao Z, Dong A, Soubigou-Taconnat L, Renou JP, Steinmetz A, Shen WH. Di- and tri- but not monomethylation on histone H3 lysine 36 marks active transcription of genes involved in flowering time regulation and other processes in Arabidopsis thaliana. Mol Cell Biol. 2008;28(4):1348-60.

58. Liu B, Wei G, Shi J, Jin J, Shen T, Ni T, Shen WH, Yu Y, Dong A. SET DOMAIN GROUP 708, a histone H3 lysine 36-specific methyltransferase, controls flowering time in rice (Oryza sativa). New Phytol. 2016;210(2):577-88

59. Lee S, Fu F, Xu S, Lee SY, Yun DJ, Mengiste T. Global regulation of plant immunity by histone lysine methyl Transferases. Plant Cell. 2016;28(7):1640-61.

60. Zhao Z, Yu Y, Meyer D, Wu C, Shen WH. Prevention of early flowering by expression of FLOWERING LOCUS C requires methylation of histone H3 K36. Nat Cell Biol. 2005;7(12):1256-60.

61. Pien S, Fleury D, Mylne JS, Crevillen P, Inze D, Avramova Z, Dean C, Grossniklaus U. ARABIDOPSIS TRITHORAX1 dynamically regulates FLOWERING LOCUS C activation via histone 3 lysine 4 trimethylation. Plant Cell. 2008;20(3):580-8.

62. Saleh A, Alvarez-Venegas R, Yilmaz M, Le O, Hou G, Sadder M, Al-Abdallat A, Xia Y, Lu G, Ladunga I, et al. The highly similar Arabidopsis homologs of trithorax ATX1 and ATX2 encode proteins with divergent biochemical functions. Plant Cell. 2008;20(3):568-79.

63. Choi SC, Lee S, Kim SR, Lee YS, Liu C, Cao X, An G. Trithorax group protein Oryza sativa Trithorax 1 controls flowering time in rice via interaction with early heading date3. Plant Physiol. 2014;164(3):1326-37.
64. Jiang P, Wang S, Jiang H, Cheng B, Wu K, Ding Y. The COMPASS-like complex promotes flowering and panicle branching in Rice. Plant Physiol. 2018;176(4):2761-71.

65. Jiang $\mathrm{P}$, Wang $\mathrm{S}$, Zheng $\mathrm{H}$, Li H, Zhang F, Su Y, Xu Z, Lin H, Qian Q, Ding Y. SIP1 participates in regulation of flowering time in rice by recruiting OsTrx1 to Ehd1. New Phytol. 2018;219(1):422-35.

66. Chen LQ, Luo JH, Cui ZH, Xue M, Wang L, Zhang XY, Pawlowski WP, He Y. ATX3, ATX4, and ATX5 encode putative H3K4 Methyltransferases and are critical for plant development. Plant Physiol. 2017;174(3):1795-806.

67. Jiang $P$, Wang $S$, Ikram AU, Xu Z, Jiang $H$, Cheng B, Ding Y. SDG721 and SDG705 are required for rice growth. J Integr Plant Biol. 2018;60(7):530-5.

68. Berr A, Xu L, Gao J, Cognat V, Steinmetz A, Dong A, Shen WH. SET DOMAIN GROUP25 encodes a histone methyltransferase and is involved in FLOWERING LOCUS C activation and repression of flowering. Plant Physiol. 2009;151(3):1476-85

69. Yun JY, Tamada Y, Kang YE, Amasino RM. Arabidopsis trithorax-related3/SET domain GROUP2 is required for the winter-annual habit of Arabidopsis thaliana. Plant Cell Physiol. 2012;53(5):834-46.

70. Pinon V, Yao X, Dong A, Shen WH. SDG2-mediated H3K4me3 is crucial for chromatin condensation and mitotic division during male gametogenesis in Arabidopsis. Plant Physiol. 2017;174(2):1205-15.

71. Jacob Y, Feng S, LeBlanc CA, Bernatavichute W, Stroud H, Cokus S, Johnson LM, Pellegrini M, Jacobsen SE, Michaels SD. ATXR5 and ATXR6 are H3K27 monomethyltransferases required for chromatin structure and gene silencing. Nat Struct Mol Biol. 2009;16(7):763-8.

72. Jacob Y, Stroud H, Leblanc C, Feng S, Zhuo L, Caro E, Hassel C, Gutierrez C, Michaels SD, Jacobsen SE. Regulation of heterochromatic DNA replication by histone H3 lysine 27 methyltransferases. Nature. 2010;466(7309):987-91.

73. Jacob Y, Bergamin E, Donoghue MT, Mongeon V, LeBlanc C, Voigt P, Underwood CJ, Brunzelle JS, Michaels SD, Reinberg D, et al. Selective methylation of histone $\mathrm{H} 3$ variant $\mathrm{H} 3.1$ regulates heterochromatin replication. Science. 2014;343(6176):1249-53.

74. Ma Z, Castillo-Gonzalez C, Wang Z, Sun D, Hu X, Shen X, Potok ME, Zhang $X$. Arabidopsis serrate coordinates histone Methyltransferases ATXR5/6 and RNA processing factor RDR6 to regulate transposon expression. Dev Cell. 2018:45(6):769-84 e766.

75. Raynaud C, Sozzani R, Glab N, Domenichini S, Perennes C, Cella R, Kondorosi $\mathrm{E}$, Bergounioux C. Two cell-cycle regulated SET-domain proteins interact with proliferating cell nuclear antigen (PCNA) in Arabidopsis. Plant J. 2006:47(3):395-407.

76. Jackson JP, Johnson L, Jasencakova Z, Zhang X, PerezBurgos L, Singh PB, Cheng $X$, Schubert I, Jenuwein T, Jacobsen SE. Dimethylation of histone $H 3$ lysine 9 is a critical mark for DNA methylation and gene silencing in Arabidopsis thaliana. Chromosoma. 2004;112(6):308-15.

77. Li S, Liu L, Li S, Gao L, Zhao Y, Kim YJ, Chen X. SUVH1, a Su (var)3-9 family member, promotes the expression of genes targeted by DNA methylation. Nucleic Acids Res. 2016;44(2):608-20.

78. Qin FJ, Sun QW, Huang LM, Chen XS, Zhou DX. Rice SUVH histone methyltransferase genes display specific functions in chromatin modification and retrotransposon repression. Mol Plant. 2010;3(4):773-82.

79. Fischer A, Hofmann I, Naumann K, Reuter G. Heterochromatin proteins and the control of heterochromatic gene silencing in Arabidopsis. J Plant Physiol. 2006;163(3):358-68.

80. Kuhlmann M, Mette MF. Developmentally non-redundant SET domain proteins SUVH2 and SUVH9 are required for transcriptional gene silencing in Arabidopsis thaliana. Plant Mol Biol. 2012;79(6):623-33.

81. Naumann K, Fischer A, Hofmann I, Krauss V, Phalke S, Irmler K, Hause G, Aurich AC, Dorn R, Jenuwein T, et al. Pivotal role of AtSUVH2 in heterochromatic histone methylation and gene silencing in Arabidopsis. EMBO J. 2005;24(7):1418-29.

82. Johnson LM, Du J, Hale CJ, Bischof S, Feng S, Chodavarapu RK, Zhong X, Marson G, Pellegrini M, Segal DJ, et al. SRA- and SET-domain-containing proteins link RNA polymerase $V$ occupancy to DNA methylation. Nature. 2014;507(7490):124-8

83. Johnson LM, Law JA, Khattar A, Henderson IR, Jacobsen SE. SRA-domain proteins required for DRM2-mediated de novo DNA methylation. PLoS Genet. 2008;4(11):e1000280.

84. Liu ZW, Shao CR, Zhang CJ, Zhou JX, Zhang SW, Li L, Chen S, Huang HW, Cai T, He XJ. The SET domain proteins SUVH2 and SUVH9 are required for pol V occupancy at RNA-directed DNA methylation loci. PLoS Genet. 2014; 10(1):e1003948, 
85. Du J, Johnson LM, Groth M, Feng S, Hale CJ, Li S, Vashisht AA, Wohlschlegel JA, Patel DJ, Jacobsen SE. Mechanism of DNA methylation-directed histone methylation by KRYPTONITE. Mol Cell. 2014;55(3):495-504.

86. Ebbs ML, Bartee L, Bender J. H3 lysine 9 methylation is maintained on a transcribed inverted repeat by combined action of SUVH6 and SUVH4 methyltransferases. Mol Cell Biol. 2005;25(23):10507-15.

87. Ebbs ML, Bender J. Locus-specific control of DNA methylation by the Arabidopsis SUVH5 histone methyltransferase. Plant Cell. 2006;18(5):1166-76.

88. Jackson JP, Lindroth AM, Cao X, Jacobsen SE. Control of CpNpG DNA methylation by the KRYPTONITE histone H3 methyltransferase. Nature. 2002; 416(6880):556-60.

89. Malagnac F, Bartee L, Bender J. An Arabidopsis SET domain protein required for maintenance but not establishment of DNA methylation. EMBO J. 2002; 21(24):6842-52.

90. Rajakumara E, Law JA, Simanshu DK, Voigt P, Johnson LM, Reinberg D, Patel $\mathrm{DJ}$, Jacobsen SE. A dual flip-out mechanism for $5 \mathrm{mC}$ recognition by the Arabidopsis SUVH5 SRA domain and its impact on DNA methylation and H3K9 dimethylation in vivo. Genes Dev. 2011;25(2):137-52.

91. Ding Y, Wang X, Su L, Zhai J, Cao S, Zhang D, Liu C, Bi Y, Qian Q, Cheng Z, et al. SDG714, a histone H3K9 methyltransferase, is involved in Tos17 DNA methylation and transposition in rice. Plant Cell. 2007;19(1):9-22.

92. Han YF, Dou K, Ma ZY, Zhang SW, Huang HW, Li L, Cai T, Chen S, Zhu JK, He XJ. SUVR2 is involved in transcriptional gene silencing by associating with SNF2-related chromatin-remodeling proteins in Arabidopsis. Cell Res. 2014; 24(12):1445-65.

93. Veiseth SV, Rahman MA, Yap KL, Fischer A, Egge-Jacobsen W, Reuter G, Zhou MM, Aalen RB, Thorstensen T. The SUVR4 histone lysine methyltransferase binds ubiquitin and converts H3K9me1 to H3K9me3 on transposon chromatin in Arabidopsis. PLoS Genet. 2011;7(3):e1001325.

94. Rahman MA, Kristiansen PE, Veiseth SV, Andersen JT, Yap KL, Zhou MM, Sandlie I, Thorstensen T, Aalen RB. The arabidopsis histone methyltransferase SUVR4 binds ubiquitin via a domain with a four-helix bundle structure. Biochemistry. 2014;53(13):2091-100.

95. Thorstensen T, Fischer A, Sandvik SV, Johnsen SS, Grini PE, Reuter G, Aalen RB. The Arabidopsis SUVR4 protein is a nucleolar histone methyltransferase with preference for monomethylated H3K9. Nucleic Acids Res. 2006;34(19):5461-70.

96. Caro E, Stroud H, Greenberg MV, Bernatavichute $\mathrm{V}$, Feng S, Groth M, Vashisht AA, Wohlschlegel J, Jacobsen SE. The SET-domain protein SUVR5 mediates $\mathrm{H} 3 \mathrm{~K} 9$ me2 deposition and silencing at stimulus response genes in a DNA methylation-independent manner. PLoS Genet. 2012;8(10):e1002995.

97. Krichevsky A, Gutgarts H, Kozlovsky SV, Tzfira T, Sutton A, Sternglanz R, Mandel G, Citovsky V. C2H2 zinc finger-SET histone methyltransferase is a plant-specific chromatin modifier. Dev Biol. 2007;303(1):259-69.

98. Zhang GQ, Liu KW, Li Z, Lohaus R, Hsiao YY, Niu SC, Wang JY, Lin YC, Xu Q, Chen LJ, et al. The Apostasia genome and the evolution of orchids. Nature. 2017:549(7672):379-83.

99. Zou LH, Wan X, Deng H, Zheng BQ, Li BJ, Wang Y. RNA-seq transcriptomic profiling of crassulacean acid metabolism pathway in Dendrobium catenatum. Sci Data. 2018:5:180252

100. Zhang GQ, Xu Q, Bian C, Tsai WC, Yeh CM, Liu KW, Yoshida K, Zhang LS, Chang SB, Chen F, et al. The Dendrobium catenatum Lindl. genome sequence provides insights into polysaccharide synthase, floral development and adaptive evolution. Sci Rep. 2016:6:19029.

101. Brown MA, Sims RJ 3rd, Gottlieb PD, Tucker PW. Identification and characterization of Smyd2: a split SET/MYND domain-containing histone H3 lysine 36-specific methyltransferase that interacts with the $\operatorname{Sin} 3$ histone deacetylase complex. Mol Cancer. 2006;5:26.

102. Hamamoto R, Furukawa Y, Morita M, limura Y, Silva FP, Li M, Yagyu R, Nakamura Y. SMYD3 encodes a histone methyltransferase involved in the proliferation of cancer cells. Nat Cell Biol. 2004;6(8):731-40.

103. Van Aller GS, Reynoird N, Barbash O, Huddleston M, Liu S, Zmoos AF, McDevitt $P$, Sinnamon $R$, Le B, Mas G, et al. Smyd3 regulates cancer cell phenotypes and catalyzes histone $\mathrm{H} 4$ lysine 5 methylation. Epigenetics. 2012;7(4):340-3.

104. Huang J, Perez-Burgos L, Placek BJ, Sengupta R, Richter M, Dorsey JA, Kubicek S, Opravil S, Jenuwein T, Berger SL. Repression of p53 activity by Smyd2-mediated methylation. Nature. 2006;444(7119):629-32.

105. Kunizaki M, Hamamoto R, Silva FP, Yamaguchi K, Nagayasu T, Shibuya M, Nakamura Y, Furukawa Y. The lysine 831 of vascular endothelial growth factor receptor 1 is a novel target of methylation by SMYD3. Cancer Res. 2007;67(22):10759-65.
106. Mazur PK, Reynoird N, Khatri P, Jansen PW, Wilkinson AW, Liu S, Barbash O, Van Aller GS, Huddleston M, Dhanak D, et al. SMYD3 links lysine methylation of MAP 3K2 to Ras-driven cancer. Nature. 2014;510(7504):283-7.

107. Zhang $X$, Tanaka $K$, Yan J, Li J, Peng D, Jiang Y, Yang Z, Barton MC, Wen $H_{\text {, }}$ Shi $X$. Regulation of estrogen receptor alpha by histone methyltransferase SMYD2-mediated protein methylation. Proc Natl Acad Sci U S A. 2013; 110(43):17284-9.

108. Ma S, Martin-Laffon J, Mininno M, Gigarel O, Brugiere S, Bastien O, Tardif M, Ravanel S, Alban C. Molecular evolution of the substrate specificity of Chloroplastic Aldolases/Rubisco lysine Methyltransferases in plants. Mol Plant. 2016;9(4):569-81.

109. Ying Z, Mulligan RM, Janney N, Houtz RL. Rubisco small and large subunit $\mathrm{N}$-methyltransferases. Bi- and mono-functional methyltransferases that methylate the small and large subunits of Rubisco. J Biol Chem. 1999; 274(51):36750-6.

110. Kim DW, Kim KB, Kim JY, Seo SB. Characterization of a novel histone H3K36 methyltransferase setd3 in zebrafish. Biosci Biotechnol Biochem. 2011;75(2): 289-94

111. Clark JW, Donoghue PCJ. Whole-genome duplication and plant macroevolution. Trends Plant Sci. 2018;23(10):933-45.

112. Lynch M, Conery JS. The evolutionary fate and consequences of duplicate genes. Science. 2000;290(5494):1151-5.

113. Mozgova I, Kohler C, Hennig L. Keeping the gate closed: functions of the polycomb repressive complex PRC2 in development. Plant J. 2015;83(1): 121-32.

114. Yu CW, Tai R, Wang SC, Yang $P$, Luo M, Yang S, Cheng K, Wang WC, Cheng YS, WU K. HISTONE DEACETYLASE6 acts in concert with histone Methyltransferases SUVH4, SUVH5, and SUVH6 to regulate transposon silencing. Plant Cell. 2017;29(8):1970-83.

115. Yang H, Howard M, Dean C. Antagonistic roles for H3K36me3 and $\mathrm{H} 3 \mathrm{~K} 27 \mathrm{me} 3$ in the cold-induced epigenetic switch at Arabidopsis FLC. Curr Biol. 2014;24(15):1793-7.

116. Hu B, Jin J, Guo AY, Zhang H, Luo J, Gao G. GSDS 2.0: an upgraded gene feature visualization server. Bioinformatics. 2015;31(8):1296-7.

117. Kumar S, Stecher G, Tamura K. MEGA7: molecular evolutionary genetics analysis version 7.0 for bigger datasets. Mol Biol Evol. 2016;33(7):1870-4.

118. Kim D, Langmead B, Salzberg SL. HISAT: a fast spliced aligner with low memory requirements. Nat Methods. 2015;12(4):357-60.

119. Pertea M, Pertea GM, Antonescu CM, Chang TC, Mendell JT, Salzberg SL. StringTie enables improved reconstruction of a transcriptome from RNA-seq reads. Nat Biotechnol. 2015;33(3):290-5.

120. Saeed Al, Sharov V, White J, Li J, Liang W, Bhagabati N, Braisted J, Klapa M, Currier T, Thiagarajan M, et al. TM4: a free, open-source system for microarray data management and analysis. BioTechniques. 2003;34(2):374-8.

121. Livak KJ, Schmittgen TD. Analysis of relative gene expression data using real-time quantitative PCR and the 2(-Delta Delta $C(T))$ method. Methods. 2001;25(4):402-8.

\section{Publisher's Note}

Springer Nature remains neutral with regard to jurisdictional claims in published maps and institutional affiliations.

Ready to submit your research? Choose BMC and benefit from:

- fast, convenient online submission

- thorough peer review by experienced researchers in your field

- rapid publication on acceptance

- support for research data, including large and complex data types

- gold Open Access which fosters wider collaboration and increased citations

- maximum visibility for your research: over $100 \mathrm{M}$ website views per year

At $\mathrm{BMC}$, research is always in progress.

Learn more biomedcentral.com/submission 